\title{
LABOR SUPPLY EFFECTS OF SOCIAL INSURANCE
}

\author{
Alan B. Krueger \\ Bruce D. Meyer \\ Working Paper 9014 \\ http://www.nber.org/papers/w9014 \\ NATIONAL BUREAU OF ECONOMIC RESEARCH \\ 1050 Massachusetts Avenue \\ Cambridge, MA 02138 \\ June 2002
}

This paper was prepared for the Handbook of Public Economics, Alan Auerbach and Martin Feldstein, editors. We thank Melissa Clark, Kenneth Fortson, Jeegar Kakkad and Bradley Heim for helpful research assistance and David Autor, Bertil Holmlund and Peter Orszag for helpful comments. We also thank Alan Auerbach for his patience and persistence in waiting for this chapter, and helpful comments. The views expressed herein are those of the authors and not necessarily those of the National Bureau of Economic Research.

(C) 2002 by Alan B. Krueger and Bruce D. Meyer. All rights reserved. Short sections of text, not to exceed two paragraphs, may be quoted without explicit permission provided that full credit, including $\mathbb{C}$ notice, is given to the source. 
Labor Supply Effects of Social Insurance

Alan B. Krueger and Bruce D. Meyer

NBER Working Paper No. 9014

June 2002

JEL No. H55, J22, J28, J65

\begin{abstract}
This chapter examines the labor supply effects of social insurance programs. We argue that this topic deserves separate treatment from the rest of the labor supply literature because individuals may be imperfectly informed as to the rules of the programs and because key parameters are likely to differ for those who are eligible for social insurance programs, such as the disabled. Furthermore, differences in social insurance programs often provide natural experiments with exogenous changes in wages or incomes that can be used to estimate labor supply responses. Finally, social insurance often affects different margins of labor supply. For example, the labor supply literature deals mostly with adjustments in the number of hours worked, whereas the incentives of social insurance programs frequently affect the decision of whether to work at all.

The empirical work on unemployment insurance (UI) and workers' compensation (WC) insurance finds that the programs tend to increase the length of time employees spend out of work. Most of the estimates of the elasticities of lost work time that incorporate both the incidence and duration of claims are close to 1.0 for unemployment insurance and between 0.5 and 1.0 for workers' compensation. These elasticities are substantially larger than the labor supply elasticities typically found for men in studies of the effects of wages or taxes on hours of work. The evidence on disability insurance and (especially) social security retirement suggests much smaller and less conclusively established labor supply effects. Part of the explanation for this difference probably lies in the fact that UI and WC lead to short-run variation in wages with mostly a substitution effect. Our review suggest that it would be misleading to apply a universal set of labor supply elasticities to these diverse problems and populations.
\end{abstract}

\author{
Alan B. Krueger \\ Economics Department \\ Princeton University \\ Princeton, NJ 08544 \\ and NBER \\ 609-258-4046 \\ akrueger@princeton.edu
}

Bruce D. Meyer

Department of Economics and Institute for Policy Research

Northwestern University

2003 Sheridan Road

Evanston, IL 60208

and NBER

bmeyer@northwestern.edu 


\section{Introduction}

This chapter summarizes evidence on the labor supply effects of social insurance programs. One may ask, "Why is a separate chapter necessary on the labor supply effects of social insurance? Why can't the labor supply parameters estimated in the voluminous labor economics literature just be plugged into the social insurance formulas?" In our view, a separate consideration of the labor supply effects of social insurance is justified for at least three reasons.

First, the generic labor supply parameters estimated in the public finance and labor economics literatures may not apply to social insurance programs because people are imperfectly informed as to the rules of the programs, or because the parameters may differ for those who are eligible for social insurance programs (i.e., heterogeneous parameters) than for the population at large. For example, a severe disability may change the way an individual perceives the trade off between labor and leisure time. More generally, the people who are on the margin of going on a social insurance program are likely to have different preferences than the wider population.

Second, the labor supply elasticities estimated in the labor economics literature span a huge range. Literature surveys such as Pencavel (1986) and Killingsworth (1983) find wide diserpsion in estimates of income and substitution effects. Fuchs, Krueger and Poterba (1998) also find that there is little agreement among economists on the magnitude of labor supply elasticities. A major shortcoming in the broader labor supply literature is that it is difficult to identify exogenous changes in wages or income that can be used to estimate labor supply responses. The variations in social insurance programs may provide natural experiments with which to estimate labor supply parameters and test the relevance of labor supply models.

Third, the design of social insurance raises several theoretical labor supply issues that are 
not often dealt with in the standard labor supply literature. For example, the prospect of receiving Social Security benefits in the future may induce some young people to enter the work force, while the provision of benefits may induce older workers to leave the work force. Moreover, much of the labor supply literature deals with adjustments in the number of hours worked per week or number of weeks worked per year, whereas the incentives of social insurance programs often affect the decision of whether to participate at all in the labor force. And programs such as Unemployment Insurance (UI) influence job search intensity, which does not figure into standard labor supply models.

To summarize the impact of social insurance on labor supply, it is necessary to have a working definition of what is meant by "social insurance." There is no official definition. For our purposes, social insurance programs are defined as compulsory, contributory government programs that provide benefits to individuals if certain conditions are met. For example, upon turning age 62 eligible individuals may receive Social Security benefits in the United States. In general, social insurance programs are funded by dedicated taxes or premiums, and have compulsory coverage. Benefits are generally restricted to those who contributed to the program's financing. Under this definition, for example, Medicare is social insurance but Medicaid is not because Medicare receipt is limited to qualified individuals who contributed to the program while Medicaid receipt is available to all individuals with sufficiently low income. Other programs that are considered social insurance include: Social Security retirement benefits, Disability Insurance (DI), Unemployment Insurance, and Workers' Compensation (WC) 
Insurance. These programs form the basis for this chapter. ${ }^{1}$ Although other programs could be classified as social insurance, such as the Railroad Employee Retirement program, these four programs are the four largest social insurance programs in the U.S., and illustrate many of the lessons that can be learned of the effect of social insurance on labor supply.

In practice, social insurance programs are the way society typically pools risks for events that have catastrophic consequences (e.g., severe work-related injuries), or events that individuals may not plan for adequately on their own (e.g., retirement). More generous benefits will provide greater protection against risk, but would likely generate larger distortionary effects. For example, generous Unemployment Insurance benefits insure workers against the earnings losses that accompany job loss, but also induce some workers to search less intensively for a new job. A great deal of research has focused on identifying and quantifying the intended and unintended consequences of social insurance. Because the receipt of social insurance is often triggered by withdrawing from work, and because the programs are typically funded by taxes on labor, a major avenue in which social insurance has its intended and unintended consequences is through altering labor supply. Another realm in which social insurance can be have an unintended effect is on savings: individuals may not save as much to offset the adverse consequences of negative events if they are insured against those risks by social insurance. See the chapter by Feldstein and Liebman in this volume for evidence on the impact of Social Security on savings behavior.

Ideally, one would like to balance the intended consequences against the unintended consequences of social insurance to design the optimal benefit level. Determining the optimal

${ }^{1}$ For the most part, the review focuses on U.S. social insurance programs, but we draw on programs in other countries when the evidence is particularly strong and germane. 
balance requires knowledge of the distortionary effects of social insurance as well as the beneficial insurance effect. The labor supply response to benefits is an important input into this calculation. Gruber (1997), for example, provides an exemplary evaluation of the tradeoff between the consumption smoothing benefit of the UI program against the undesired distortion to job search intensity caused by the provision of benefits. Knowledge of the labor supply effects of social insurance is required for governments to optimally design the programs.

The provision of social insurance is a major government function. Figure 1.1 displays the percent of the U.S. federal government budget devoted to social insurance expenditures each year since $1967 .^{2}$ In 1967, 15 percent of government expenditures consisted of social insurance outlays. By 1996, social insurance expenditures rose to one third of total government spending, and in 2007 social insurance benefits are predicted to top 44 percent of government spending. The growth in social insurance spending is primarily a result of demographic shifts (e.g., an aging population), increases in program generosity, rising health care costs, and behavioral responses to program changes. Paul Krugman (2001) did not exaggerate when he observed, "loosely speaking, the post-cold-war government is a big pension fund that also happens to have an army."

The U.S. is not unique in devoting a great deal of the government budget to social insurance. The first column of Table 1.1 reports the percent of social insurance spending as a percent of GDP in eight countries, which were selected because they span a wide range of economic development and had available data. The next two columns report social insurance

${ }^{2}$ Here social insurance includes Old Age Survivors and Disability Insurance, Medicare, Workers' Compensation Insurance and Unemployment Insurance benefits. 
expenditures as a percent of the central government's budget and as a percent of the budget in all levels of government. The social insurance expenditure data are from the International Labour Organization, and cover a broader range of activities than the measure used in Figure 1.1. In social democratic countries like Sweden and Germany, social insurance expenditures represent a much greater share of government and economic activity than they do in the U.S. In developing countries, social insurance expenditures are a smaller share. Transitioning countries, such as the Czech Republic, appear to be an intermediate case. Social insurance expenditures are surprisingly low in Japan, reflecting in part that country's meager public pension system. Overall, the table gives the impression that social insurance is a normal good, representing a higher share of the government's budget and economic activity in wealthier countries. ${ }^{3}$ Not surprisingly, social insurance expenditures have risen over time in many countries as well.

It is natural to question whether the increase in expenditures on social insurance programs has influenced the declining trend in labor force participation. Figure 1.2 illustrates long-term trends in labor force participation of older men in the U.S. using a series developed by Moen (1987) and Costa (1998). ${ }^{4}$ The figure shows the percent of men age 55-64 or 65 and older who are gainfully employed each Census year. Employment has declined considerably for older men since the beginning of 20th century. Similar -- and in some cases sharper -- downward trends

${ }^{3}$ Looking across countries, Rodrik (1997) and Agell (1999) find a positive relationship between the generosity of a variety of social welfare benefits and the openness of the economy, suggesting that social insurance is demanded, in part, to dampen the risk associated with trade shocks.

${ }^{4}$ Quinn (1999) finds that the downward trend in labor force particpation of older workers has levelled off or reversed since the mid 1980s. Although this is a very interesting development, our interest here is in the longer term pattern. 
have occurred in other industrialized countries. The declining employment of older men raises three issues of concern for public economics: first, a smaller proportion of the workforce is available to contribute support for social insurance and other government programs; second, more individuals receive Social Security retirement benefits, raising the need for tax revenues; and third, social insurance may distort the economy by inducing some individuals to exit the labor force prematurely. ${ }^{5}$ An earlier wave of studies (e.g., Parsons, 1980 and Hurd and Boskin, 1984) attempted to explain the fall in aggregate labor force participation by rising social insurance benefits.

As social insurance consumes an even larger share of government budgets, and as the size of the working-age population declines relative to the nonworking-age population, understanding labor supply responses to social insurance will take on even greater importance.

The organization of the remainder of this Chapter is as follows. We first discuss Unemployment Insurance in Section 2, beginning by describing the main program features and how they differ across the states. We also provide some brief information on programs in Canada and other countries. We then discuss the main effects of UI on labor supply, first from a theoretical perspective and then by reviewing the empirical evidence. Section 3 follows the same pattern for Workers' Compensation. We begin by describing the main characteristics of state programs, and then lay out the theoretical predictions and empirical evidence on labor supply responses. In Section 4 we examines Social Security. We describe the theoretical predictions and empirical evidence on labor supply effects. We end this section with a discussion of the timing of retirement and the effects of the earnings test. In Section 5 we examine Disability

${ }^{5}$ For a more benign interpretation, see Burtless and Munnell (1991). 
Insurance. We describe the operation of the program and then analyze the evidence on its role in explaining trends in labor force participation and self-reported disability rates. Section 6 provides our conclusions.

\section{Unemployment Insurance}

Unemployment insurance is one of the most extensively studied government programs in the U.S. and elsewhere. Before describing the main features of UI programs and their labor supply effects, we should note that there are several excellent prior surveys of UI. ${ }^{6}$ Though many of the surveys cover a wide range of issues, they generally emphasize the labor supply effects of UI.

\subsection{Main Features of U.S. Unemployment Insurance Programs}

UI programs differ sharply across states due to the provisions of the Social Security Act of 1935 which created the current system and gave states great latitude in designing their programs. State UI programs differ in the earnings required for eligibility, the level of benefits (the replacement rate, the minimum and maximum benefit), the potential duration of benefits, and other parameters. Table 2.1 reports key features of twelve state programs in 2000. It is apparent from this table that there are large differences in program parameters across states. These cross-state differences and their frequent changes over time have been a fundamental

${ }^{6}$ See Hamermesh (1977), Welch (1977), Danziger, Haveman, and Plotnick (1981), Gustman (1983), Atkinson (1987), Atkinson and Micklewright (1990), Devine and Kiefer (1991), Anderson and Meyer (1993), and Holmlund (1998) for surveys of the UI literature. 
source of the identifying variation used to estimate the effects of these programs.

Approximately 97 percent of all wage and salary workers are in jobs that are covered by unemployment insurance. The main categories of workers not covered are the self-employed, employees of small farms, and household employees whose earnings are below the threshold amount. Despite this near universal coverage, less than forty percent of the unemployed received UI in many recent years. ${ }^{7}$ The cause of this low rate of receipt is largely that individuals who are new entrants or reentrants to the labor force, who have irregular work histories, and individuals who quit or are fired from their last job are typically not eligible for benefits. Such individuals are frequently excluded by minimum earnings requirements for eligibility ranging from $\$ 130$ in Hawaii to $\$ 3,400$ in Florida, with a typical state requiring previous earnings just over $\$ 1,500 .^{8}$

UI benefits are paid on a weekly basis, and except for minimum and maximum benefit amounts, are usually between 50 and 60 percent of previous earnings. ${ }^{9}$ All states have a maximum weekly benefit amount, which varies from a low of $\$ 190$ in Mississippi to over $\$ 600$ in Massachusetts if dependents' allowances are included. The median state had a maximum benefit of about $\$ 292$ in 2000 . About 35 percent of claimants receive the maximum benefit. For these individuals, the fraction of their previous earnings replaced by UI can be much lower than

\footnotetext{
${ }^{7}$ See Blank and Card (1991) and Anderson and Meyer (1997) for studies of the reasons for the low rate of UI receipt.

${ }^{8}$ More precisely, earnings during the first four of the five full calendar quarters prior to the quarter an individual files for benefits. Five states now use alternative time frames that differ from this rule.

${ }^{9}$ A typical benefit schedule would compute the weekly benefit amount as high quarter earnings divided by 23 . High quarter earnings are typically the highest calendar quarter of earnings during the first four of the five full calendar quarter prior to the quarter an individual files for benefits.
} 
50 percent. The minimum weekly benefit is typically very low; the median state has a minimum of about $\$ 39$.

In almost all states, benefits last up to 26 weeks. However, in all but eight states, total benefits paid are restricted to some fraction of previous earnings or weeks worked. Table 2.1 indicates that a typical state requires just over 3 quarters (39 weeks) of work for a claimant to be eligible for 26 weeks of benefits. This provision causes the potential duration of benefits to be less than 26 weeks for approximately half of all recipients. ${ }^{10}$ In all but 11 states, there is a waiting period of one week after the beginning of unemployment until one can receive benefits.

In 1970, a permanent Federal-State extended benefits program was established to provide additional weeks of benefits to individuals who exhaust their regular State benefits in periods of high unemployment. When a state's insured unemployment rate is sufficiently high, weeks of benefits are extended 50 percent beyond that which an individual would be entitled to under State law, with the extension not to exceed 13 weeks. In addition, in times of high unemployment Congress has typically passed ad hoc laws temporarily extending benefits further. Because the unemployment rate has been low in recent years, benefits have only rarely been extended, despite a change that relaxed the threshold for benefit extensions in 1993.

Prior to 1979, UI benefits were not subject to Federal income taxation, but in 1979 they became taxable for high income individuals. In 1982 taxation of UI was extended to most

${ }^{10} \mathrm{~A}$ typical state calculates potential weeks of benefits as the minimum of 26 and base period earnings divided by three times the weekly benefit amount. Base period earnings are usually calculated as earnings during the first four of the five calendar quarters prior to the quarter an individual files for benefits. 
individuals, and in 1987 benefits became taxable for all recipients. ${ }^{11}$ UI benefits are not, however, subject to OASDHI (Social Security and Medicare) payroll taxes.

A convenient indicator of the work disincentive of UI is the fraction of previous after-tax earnings replaced by after-tax benefits, the after-tax replacement rate. This replacement rate has fallen dramatically in recent years, particularly due to the taxation of benefits, and is now typically under one-half. As recently as 1986, some people had replacement rates near one (often those lifted by the minimum benefit), implying that they would receive from UI nearly what they would earn if they returned to work. ${ }^{12}$ This situation is much less common today. Strong disincentives to work part-time remain, though, as benefits are typically reduced dollar for dollar for earnings greater than a fairly small amount (the earnings disregard).

\section{$2.2 \quad$ UI Financing}

UI financing in the U.S. is unique in that a firm's tax rate depends on its layoff history. In other countries benefits are funded through general revenues or payroll taxes that are not determined by a firm's layoffs. The dependence of a firm's tax rate on previous UI use is called experience rating. Federal law levies a 6.2 percent tax on the first $\$ 7,000$ in wages a year paid to an employee. The law provides for a credit of 5.4 percent to employers that pay State taxes under

\footnotetext{
${ }^{11}$ In 1979 UI benefits became taxable for married taxpayers filing jointly with income over $\$ 25,000$, and single filers with income over $\$ 20,000$. In 1982 the cutoffs changed to $\$ 18,000$ and $\$ 12,000$ respectively.
}

${ }^{12}$ See Feldstein (1974) for an earlier discussion and evidence on high replacement rates. 
an approved UI system, so that all employers pay at least 0.8 percent.

State experience rating systems take many forms, but the two most common are reserve ratio (30 states and D.C.) and benefit ratio experience rating (17 states). ${ }^{13}$ In reserve ratio systems, a firm's tax rate depends on the difference between taxes paid and benefits accrued divided by average covered payroll. Taxes paid and benefits accrued are typically summed over all past years and are not discounted, whereas average payroll is typically the average over the last three years. In benefit ratio systems, a firm's tax rate depends on the ratio of benefits paid to taxable wages, both generally averaged over the last three years.

In reserve ratio states, a firm's tax rates increases in steps as its reserve ratio decreases (in benefit ratio states tax rates rise as the benefit ratio rises). However, for most firms in almost all states, the tax rates do not adjust sufficiently when the ratios change to cause firms to pay the full marginal UI costs of laying off a worker. In addition, there are large ranges at the top and bottom, over which a firms layoff history has no effect on its tax payments. This provides an incentive to temporarily lay off workers, and subsidizes industries with seasonal variation in employment. Forty states have a tax base that is higher than the Federal base of $\$ 7,000$. Alaska has the highest at $\$ 22,600$. Overall, in 1998 UI taxes were a highly regressive 1.9 percent of taxable wages, and 0.6 percent of total wages. ${ }^{14}$

\subsection{UI Programs Outside of the U.S.}

${ }^{13}$ See National Foundation for Unemployment Compensation \& Workers' Compensation (2000). Michigan and Pennsylvania are counted as benefit ratio states even though they have hybrids of reserve ratio and benefit ratio systems. and benefits.

${ }^{14}$ See Anderson and Meyer (2001) for an analysis of the distributional effects of UI taxes 
We should emphasize that there are often very different institutions in other countries to insure the unemployed. Moreover, programs for the unemployed are often combined with other programs, and those eligible for one type of benefit are often eligible for another in certain circumstances. These features often make cross-country comparisons problematic. Subject to these caveats, in Table 2.2 we report UI expenditures as a share of GDP and in absolute terms in 7 countries. ${ }^{15}$ Analogous expenditures on compensation for work injuries are reported for comparison. There are pronounced differences across countries. Among these countries, the U.K. has the lowest share of GDP devoted to UI expenditures at 0.25 percent, while four other countries have shares at least ten times as big. Part of the explanation for the low GDP share in the U.K. is that they provide a benefit that does not vary with previous earnings and is set at a fairly low level. For example, a single individual over age 25 was entitled to a weekly benefit of $£ 52.2$ (\$77) in 2000. This amount is only slightly higher than a typical minimum benefit in the U.S.

One of the countries with a GDP share over 2.5 percent is Canada. The Canadian UI program provides an interesting comparison as Canada is a close neighbor of the U.S. and has a similar per capita income and industry base. Surprisingly, Canadian expenditures are almost one-half of those in the U.S. despite Canada having a population less than 11 percent as large. While Canadian weekly benefits are slightly higher and last slightly longer on average than U.S. benefits, the major difference between the countries is in the ratio of UI recipients to the number of unemployed. An unemployed individual is approximately three and one-half times more

\footnotetext{
${ }^{15}$ For summary measures of the replacement rate and benefit duration in OECD countries, Nickell (1998) provides a nice overview.
} 
likely to receive benefits in Canada than in the U.S. This difference is hard to explain on the basis of the composition of unemployment in the two countries or current statutory qualification rules, though Canadian benefits were certainly more generous in the 1970s and 1980s than those in the U.S.. The amount of earnings in the past needed to qualify for benefits is only slightly higher in Canada. Those who have left their previous job are usually not eligible in the U.S., but are often eligible in Canada. It is also true that without experience rating, Canadian employers have less incentive to enforce eligibility rules. However, these features appear to only explain a small part of the difference. Furthermore, the timing of when UI became more generous in Canada than in the U.S. does not fit particularly well with when the two countries' unemployment rates diverged. ${ }^{16}$

\subsection{Theoretical Responses of Labor Supply to UI}

UI affects at least five dimensions of labor supply. First, UI can increase the probability of unemployment by affecting worker and firm actions to avoid job loss. Second, program characteristics affect the likelihood that workers will file a claim for benefits once a worker is laid off. Once a claim has been made, we expect that labor supply will be affected by the adverse incentives of the UI program. Third, once on the program, UI can extend the time a person is out of work. Most research on the labor supply effects of UI has focused on this issue. Fourth, the availability of compensation for unemployment can shift labor supply by changing the value

\footnotetext{
${ }^{16}$ See Card and Riddell (1993, 1997), Riddell and Sharpe (1998) and Riddell (1999) for detailed comparisons of the U.S. and Canadian UI systems and discussions of the role of UI in explaining unemployment rate differences between the two countries.
} 
of work to a potential employee. Finally, there are additional affects such as the work responses of spouses of unemployed workers. We discuss these five effects in turn. ${ }^{17}$

First, we discuss the effect of UI on the incidence of unemployment. UI can induce eligible workers to search less hard for a different job or work less hard on the current job, both of which can lead to a layoff. There has been some modeling of this issue; for example, Mortensen (1990) examines the effect of UI on search while employed. However, these effects have not been extensively studied. There is a substantial theoretical literature on how the availability of UI may make layoffs more common when firms face variable demand for their product. The presence of UI, particularly UI that is not fully experience rated, may make firms more likely to layoff workers and employees more willing to work in layoff-prone firms (see Baily 1977; Feldstein 1976). While this response to UI is partly a labor demand effect, it is also partly a labor supply response as workers are induced to take jobs with higher layoff risk because of UI. ${ }^{18}$

Second, the generosity of UI benefits may affect the probability that a person claims benefits conditional on a layoff. As the generosity of benefits rises, it is more likely that the stigma and transaction costs of applying for UI will be outweighed by the benefits. Furthermore, whether someone initially receives UI is partly related to how long they are out of work. A UI claimant in nearly all states must be out of work over a week to be eligible for benefits. ${ }^{19}$ It is

\footnotetext{
${ }^{17}$ This classification of the labor supply effects of UI leaves out some effects that can be considered labor supply such as possible improvements in the matching of workers to jobs.

${ }^{18}$ This effect of UI occurs through an outward shift in the labor supply curve to high layoff jobs, so it partly falls under the fourth effect of UI below.

${ }^{19}$ This waiting week can be thought of as the deductible in the UI insurance policy.
} 
more likely that a person will remain out of work for the waiting week if benefits are high. In addition to affecting program costs, the increased claim rate in turn affects weeks worked, because once a person is on the UI rolls, they become subject to the implicit taxes on work and the consequent work disincentives.

Third, conditional on beginning an unemployment spell, the duration of time out of work is affected by UI. This issue has received the most attention in the UI literature. Both labor supply and search models suggest that higher and longer duration UI benefits will cause unemployed workers who receive UI to take longer to find a new job. An elegant, yet fairly realistic search model is provided by Mortensen (1977), though there are many search models incorporating unemployment insurance. ${ }^{20}$ Mortensen models workers as choosing a search intensity and a reservation wage while facing a stationary known wage offer distribution and a constant arrival rate of job offers (for a given search intensity). If the worker is offered a job at a wage that exceeds the reservation wage, he or she accepts it. Mortensen incorporates two key features of the UI system in the United States into the model: benefits are assumed to be paid only for a specified duration rather than in every period of an unemployment spell, and new entrants or workers who quit jobs are not qualified for benefits. ${ }^{21}$

In this framework, the main labor supply effect of UI is to lengthen unemployment spells. This effect can be seen in the model as increases in either the level or potential duration of benefits raise the value of being unemployed, reducing search intensity and increasing the reservation wage. Thus, the exit rate from unemployment,

\footnotetext{
${ }^{20}$ See Mortensen (1986), for example.
}

${ }^{21}$ See Burdett (1979) for an analysis of a similar model. 
$\lambda(\mathrm{s})[1-\mathrm{F}(\mathrm{w})]$,

falls, as both s and $[1-\mathrm{F}(\mathrm{w})]$ fall, where $\lambda(\cdot)$ converts search effort s into job offers, $w$ is the reservation wage and $\mathrm{F}$ is the cumulative distribution function of wage offers.

Mortensen's model also implies a second labor supply effect of UI, known as the "entitlement" effect. This effect of UI raises the escape rate from unemployment for workers who currently do not qualify for benefits and for qualified workers close to when benefits are exhausted. That is, because the potential for receiving benefits on a future job makes work more attractive, workers who are ineligible for UI search harder to find a job. Higher benefits reduce the escape rate for recipients when time until exhaustion is high and increase the escape rate around the time of exhaustion. This pattern of UI effects on the hazard of leaving unemployment is illustrated in Figure 2.1. Since the entitlement effect is likely to be small relative to the standard search subsidy effect in many countries, the average duration of unemployment is likely to rise with increases in both the level and potential duration of benefits. The effect of UI on unemployment durations has also been modeled using the standard static labor supply model. In a version of this model, Moffitt and Nicholson (1982) assume people to have preferences over two goods, income and leisure. Unemployment in this model raises utility because of its leisure value. The wage on a new job is fixed and a job can be found at any time. At the time of job loss, an individual chooses income and weeks of unemployment subject to a budget constraint that can be seen in Figure 2.2. The budget constraint becomes flatter as the level of UI benefits increases and is extended outward as the potential duration of benefits increases. Both effects make unemployment more attractive, thus making it more likely that an individual will choose to be unemployed longer. 
The two models make very different assumptions but have similar predictions. In the Mortensen model the individual is uncertain when a job will be found and what the wage will be. One remains unemployed until a sufficiently high paying job is found. In the Moffitt and Nicholson model one can find a job anytime at a fixed wage. Their model emphasizes the leisure value that a period of unemployment may have if one optimizes over a long period of time such as a year. This explanation has its greatest plausibility when there is a significant demand for home production or it is difficult to take a vacation once a new job has begun. ${ }^{22}$

One should note that unemployment benefits affect the labor supply of employed and unemployed workers in other ways. We already mentioned the Mortensen entitlement effect where unemployed workers who are currently not eligible for benefits search harder because a job with UI is more valuable. In a standard labor supply framework, a similar mechanism would shift out the labor supply curve of the unemployed. This type of affect should also apply to the employed. Because UI makes employment more attractive if individuals realize that they may be laid off sometime in the future, the labor supply curve shifts outward (ignoring financing). Anderson and Meyer (1997), following Summers (1989) and Gruber and Krueger (1991), describe how labor supply may shift in this way in response to the provision of benefits.

UI may also reduce work by spouses and limit part-time work. One of the responses to unemployment in the absence of UI may be an increase in hours worked by the spouse of an unemployed worker. This spousal labor supply is likely to be "crowded out" at least in part by unemployment benefits that reduce the loss in family income when one spouse is unemployed.

\footnotetext{
${ }^{22}$ Implicit in this discussion is the assumption that the search requirement for UI receipt
} can be satisfied at low cost. 
As for part-time work, the incentives mentioned earlier discourage part-time work. In particular, one would expect that when there is a decrease in the allowable earnings before an individual's benefits are reduced (the disregard), there will be an decrease in part-time work and a smaller increase in full-time work (McCall, 1996). In addition, those seeking part-time work are ineligible for benefits in most states. These workers' earnings are taxed to finance the program, yet they are disqualified from receiving benefits. This issue has aroused controversy in recent years.

Finally, we should emphasize that the above results are based on partial equilibrium analyses, i.e. they do not include the effect of the behavior of UI recipients on those that do not receive UI. This issue is discussed briefly below.

\subsection{Empirical Evidence on UI Labor Supply Effects}

There are excellent earlier surveys that include summaries of the labor supply effects of UI, as was mentioned above. Atkinson (1987), in particular, provides concise summaries of the literature up through the mid-1980s. In this survey we will not replow that ground, but rather focus on mostly newer studies, though we will discuss the results in relation to some of the earlier summaries of the literature.

\subsubsection{Identification of Unemployment Insurance and Workers' Compensation Effects}

Before discussing estimates of UI program effects, it is useful to make some general 
comments that apply to both the UI and WC literatures. While good evidence on UI and WC effects from outside the English-speaking countries is becoming more common (especially for UI), there are reasons to believe that the best evidence on the effects of UI and WC-especially for programs with features similar to those in the states--is likely to come from the U.S. With 50 states and the District of Columbia having essentially the same systems but with often sharply different benefit levels and other characteristics, one has transparent variation in incentives that is arguably exogenous and can be used to estimate the effects of UI and WC. Moreover, there are often differing incentives across groups within a state, and sharp changes in program characteristics for one group, but not another, providing additional levers to identify the effects of the programs.

That states differ in many respects, and that their policies are often driven by these differences, does not invalidate many of the approaches that can be taken with U.S. data. There certainly is work showing that state UI and WC benefits are affected by underlying state attributes. ${ }^{23}$ Nevertheless, the best work using data from the States relies on sharp changes in policies (and uses comparison groups), while the underlying determinants of policies tend to move slowly. For example, studies using data immediately before and after benefits have been increased sharply are likely to be immune from a political economy critique, especially when the forces that lead to these policy changes are understood. Other sensible approaches include, for example, the examination of policies that affect one group but not another or have sharply different effects on different groups. For example, U.S. benefit schedules generally do not provide high benefits for all of those in a particular state. Rather, they provide very different

\footnotetext{
${ }^{23}$ For example, see Adams (1986) for UI, and Besley and Case (1994) for WC.
} 
benefit replacement rates depending on one's earnings, and these schedules differ sharply across states and over time.

This is not to say that U.S. evidence is applicable to all countries or that non-U.S. studies cannot be convincing. Only a narrow range of policies can be directly evaluated using U.S. data because state differences in UI programs are all within the confines of the parameters of a federal system and because state WC programs are similar (due in part to influential commissions, the efforts of national insurance organizations, unions, and multi-state employers). Furthermore, the economic, cultural and institutional background in other countries may render the U.S. experience not directly transferable. Nevertheless, in the vast majority of non-U.S. studies (and many U.S. studies) it is difficult to see the identifying variation in UI or WC program characteristics across units that allows researchers to estimate program effects. Atkinson and Micklewright (1985), in their review of UI research, argue that micro-data studies that do not describe their sample and other basic facts are "likely to be meaningless" (p. 241). We would stress that the same is true of studies that do not make clear the source of differences in program incentives across individuals and why those sources are likely to be exogenous. Other problems arise in cross-country studies that have difficulty holding constant the many country specific features that affect unemployment.

Before describing the central tendencies of the empirical work on UI and WC labor supply effects, we describe an empirical approach that has been used successfully in a number of recent studies. Specifically, a number of recent studies have examined changes in state laws that affected some individuals, but not others, or reforms that provided plausible comparison groups through another means. 
A useful place to start is the numerous papers that examine the effects of unemployment insurance (UI) on the length of unemployment spells. In a typical study that does not use exogenous variation from policy changes, the length of unemployment benefits is regressed on the benefit level or the replacement rate, the past wage or earnings, and demographic characteristics. Welch (1977) criticizes this conventional methodology by pointing out that within a given state at a point in time, the weekly UI (or WC) benefit is a constant fraction of previous earnings except when an individual receives the minimum or maximum weekly benefit. Thus, regressions of spell length on weekly benefits and previous earnings consequently cannot distinguish between the effect of UI and WC and the highly correlated influence of previous earnings. This result is especially true if we are uncertain about exactly how previous earnings affect spell length. As we discuss below, this identification problem, which is created by the dependence of program generosity on an individual's previous earnings, is common to many social insurance programs besides UI and WC, including social security and disability insurance. Other sources of differences in benefits, such as family composition and earnings, are also likely to have independent effects on spell length making their use in identification suspect. In many studies of UI outside the U.S., eligibility for UI or benefit generosity are often taken as exogenous even though they depend on an individual's work history and place of employment. This problem also arises when other outcomes are examined, such as savings.

Several papers exploit potentially exogenous variation in UI benefit levels from increases in state maximum weekly benefit amounts. These natural experiments are used to estimate the effects of UI on the length of unemployment, reemployment earnings, and the incidence of UI claims. Early work in the spirit of this approach can be found in Classen (1979) and more 
closely Solon (1985). Classen examines benefit changes, but relies mostly on departures from a linear effect of earnings on outcomes as a measure of benefit effects. Solon examines the length of UI receipt in Georgia just before and after the introduction of federal income taxation of UI for high income individuals in 1979. In the typical study of spell lengths, the variation in UI benefits comes from some combination of different replacement rates in different states, different minima and maxima, and maybe some variation in these parameters over time. Many of the natural experiment type papers are able to isolate one component of this variation which can separately be used to identify the effects of UI.

The main idea for one of the natural experiment papers that we use as a prototype can be seen by examining Figure 2.3, which displays a typical state schedule relating the weekly UI (or WC) benefit amount to previous earnings. The solid line is the schedule prior to a change in a state law which raises the minimum and maximum weekly benefit amount (WBA). The dashed line is the schedule after the benefit increase. Between the minimum and the maximum, the weekly benefit amount is a constant fraction of previous earnings (in the case of UI in most states, the highest quarter of earnings during the first four of the last five calendar quarters prior to the date of filing for benefits).

For people with previous earnings of at least $\mathrm{E}_{3}$ (the High earnings group), one can compare the mean weeks of UI received and reemployment earnings of people who filed for UI benefits just prior to and just after the change in the benefit schedule. ${ }^{24}$ Those who file before the increase receive $\mathrm{WBA}^{\mathrm{B}}{ }_{\max }$ while those filing afterwards receive $\mathrm{WBA}^{\mathrm{A}}{ }_{\max }$. An individual's filing

\footnotetext{
${ }^{24}$ In principle, one could also examine the effects of increases in the minimum weekly benefit amount. However, in many cases few people receive the minimum benefit and it is raised infrequently.
} 
date generally determines his UI benefit amount for his entire benefit year (the one year period following date of claim). Thus, two individuals with quarterly earnings greater than $\mathrm{E}_{3}$ will receive different weekly benefits for their entire period of receipt if one filed a few days before and the other a few days after the effective date of the benefit increase. This is the main idea of this approach. Most of the remaining methodological issues in the approach involve correcting for possible differences between the individuals filing just before and just after the benefit increase. One may also need to account for the dependence between observations from a given earnings group for a given year. In this example, one can use as a comparison group those with earnings between $E_{1}$ and $E_{2}$ (the Low earnings group) who file just before and just after the benefit increase. The benefits these individuals receive are unaffected by the increase in the maximum benefit amount. The so-called difference-in-differences estimator would then be used. In studies of this type, an additional comparison group may come from states that did not experience a benefit increase.

One should not construe this argument as saying that all studies that use this type of approach are convincing, and studies that do not are not convincing. Rather, this example shows that one can make clear the sources of variation that allow the estimation of program effects, and that one can then make a case for their exogeneity (or lack theoreof).

\subsubsection{Unemployment Insurance and Unemployment or Claim Incidence}

There is a substantial literature that finds a large effect of UI on the incidence of unemployment or the incidence of UI claims. Table 2.3 summarizes some of these studies. 
These studies are mostly concerned with labor demand, but we include them for completeness. Feldstein (1978) examines the effect of benefits on layoffs, finding a large effect. The subsequent studies focus on how incomplete experience rating interacts with benefit generosity to affect layoffs. In these studies a key variable is the marginal tax cost of a layoff, denoted by e, which is the fraction of the UI cost of an additional layoff (in present value) that a firm can expect to pay in future taxes. The extent to which e is below one, then, is a measure of the degree to which experience rating is incomplete. The three studies, Topel (1983), Card and Levine (1994), Anderson and Meyer (1994) all find large effects of incomplete experience rating on layoffs. The first two studies find substantially larger effects using state by industry proxies for the tax cost than is found by the third study which employs firm level tax costs. It is hard to translate these results into effects of the level of benefits, but it should be clear that incomplete experience rating could not have an effect on layoffs unless there were substantial UI benefits. In a paper that is explicitly about labor demand, Anderson (1993) finds that UI induced adjustment costs have a substantial effect on the seasonality of employment.

A second group of studies, summarized in Table 2.4, examines how UI benefits and other variables affect the frequency of claims for UI conditional on unemployment or a job separation. Corson and Nicholson (1988) and Blank and Card (1991) both examine aggregate data and Panel Study of Income Dynamics (PSID) microdata. They both find substantial effects of the level of benefits in aggregate data, but come to conflicting results using the microdata. Anderson and Meyer (1997) find substantial effects in administrative microdata. Overall, an elasticity of unemployment or claims with respect to benefits in the neighborhood of .5 is a reasonable summary of these studies. 


\subsubsection{Unemployment Insurance and Unemployment Durations}

The results of many of the more recent studies of unemployment durations as well as some older studies that rely on changes in benefits for identification are reported in Table 2.5. Focusing on the U.S. studies first, the studies imply an elasticity of duration with respect to the level of benefits in excess of 0.5. Several of the studies, including Classen (1979), Solon (1985), and Meyer $(1989,1990)$ find elasticities over 0.5 . The elasticity estimates with respect to the potential duration (length) of benefits tend to be much lower.

The non-American results reported in Table 2.6 are more varied. Very large effects of potential duration in Canada but no benefit level effect is found by Ham and Rea (1987), while Hunt (1995) finds very large effects of the level and potential duration of benefits in Germany. The studies of Sweden (Carling et al., 1996) and Norway (Roed and Zhang, 2000) find much smaller effects, though the sources of identification in the former study are far from clearly exogenous. A very thoughtful recent study by Carling, Holmlund and Vejsiu (2001) examines data before and after a benefit cut in Sweden and finds an elasticity over 1.0. The authors discuss a paper written in Swedish that analyzes an earlier cut and also finds large effects. Other work by Abbring, van den Berg, and van Ours (2000) suggests large effects of benefit cuts on unemployment duration in the Netherlands, but it is difficult to separate out benefit cuts from other policies in their work. An elasticity of unemployment duration with respect to benefits of 0.5 is not an unreasonable rough summary, though there is a wide range of estimates in the literature. Such an elasticity is not very different from the central tendency of the duration elasticities reported in the Atkinson (1987) survey. 
One should note that the elasticity of unemployment with respect to benefits is the sum of the layoff/claim elasticity and the duration elasticity. To see this result, let weeks unemployed $\mathrm{W}$ be the product of incidence, I, and duration, D. Then, letting the UI benefit be B, we have $\mathrm{W}=\mathrm{I} \cdot \mathrm{D}$, and $[\mathrm{dW} / \mathrm{dB}][\mathrm{B} / \mathrm{W}]=[\mathrm{B} / \mathrm{W}][\mathrm{DdI} / \mathrm{dB}+\mathrm{IdD} / \mathrm{dB}]=[\mathrm{B} / \mathrm{I}][\mathrm{dI} / \mathrm{dB}]+[\mathrm{B} / \mathrm{D}][\mathrm{dD} / \mathrm{dB}]$.

Overall, the combined effect of benefits on unemployment through incidence and duration is suggested to be near one by these studies. This result is consistent with the aggregate analysis of twenty OECD countries by Nickell (1998) who finds an elasticity of unemployment with respect to the replacement rate of close to one.

Besides cross-sectional regression analyses of benefit effects on duration, we also have evidence from a recent series of randomized social experiments in the U. S. that are surveyed in Meyer (1995b). Four cash bonus experiments made payments to UI recipients who found jobs quickly and kept them for a specified period of time. Six job search experiments evaluated combinations of services including additional information on job openings, more job placements, and more extensive checks of UI eligibility. The bonus experiments show that economic incentives do affect the speed with which people leave the unemployment insurance rolls. As a result, UI is not a completely benign transfer, but rather it affects claimants' behavior as shown by the declines in weeks of UI receipt found for all of the bonus treatments. The job search experiments found that various combinations of services to improve job search and increase enforcement of work search rules reduce UI receipt. It is hard to extrapolate from these experimental results to elasticities since the treatments were very different from benefit changes, but the estimates probably suggest moderate effects of UI. Individuals clearly were able to 
change the speed with which they went back to work when faced with financial incentives to do so, but the effects were not particularly large. The experiments also indicated that job search assistance and reporting requirements have a substantial effect on unemployment duration.

\subsubsection{Unemployment Insurance Spillovers}

An important issue on which more evidence is needed is the degree of spillover effects from UI recipients to other unemployed individuals. Might the spells of non-recipients become shorter, if UI recipients cut back on search activities and thus competed less strenuously for available jobs? The possibility of such spillovers has been emphasized by Atkinson and Micklewright (1985) and others. Levine (1990) examines this question empirically using the CPS and the National Longitudinal Survey of Youths. He finds that increases in the generosity of UI benefits appear to decrease the unemployment of those who do not receive UI. This is important work that suggests that previous work on UI and unemployment durations may have overestimated the overall effects of UI on unemployment rates. There is little other direct evidence on the question of whether general equilibrium effects of UI are much smaller than partial equilibrium effects. We should note that it is also possible that the adverse unemployment effects of UI will be magnified in general equilibrium. Carling et al. (2001) argue that UI will raise wage pressure in economies where wage bargaining is pervasive, thus reinforcing its adverse incentive effects on job search. 


\subsubsection{Other Labor Supply Effects of Unemployment Insurance}

Table 2.7 summarizes two studies of other aspects of labor supply that are affected by UI. Cullen and Gruber (2000) find that higher unemployment benefits are associated with less work by the wives of unemployed men. The authors find that there is substantial crowd-out of this form of family "self-insurance." Their estimates suggest that for every dollar of UI received by the husband, wives earnings fall by between 36 and 73 cents. McCall (1996) examines the effects of UI on part-time work. He finds that the level of the disregard (the amount of earnings allowed before benefits are reduced) has a significant effect on the probability of part-time employment during the first three months of joblessness. There is also some work on the extent to which the presence of UI shifts out labor supply of those who are employed (Anderson and Meyer, 1997) and those whose benefits are about to run out (Katz and Meyer, 1990). The first paper finds some support for potential workers' valuing the benefits (and labor supply thus shifting out), but the estimates are imprecise. The second paper finds little support for the hypothesis that higher UI benefits raise job-finding just prior to benefit exhaustion.

\section{Workers' Compensation}

\subsection{Main Features of U.S. Workers' Compensation Programs}

States have complete discretion in designing their workers' compensation programs. Nevertheless, state programs have many standard features. Coverage under workers 
compensation in the U.S. is about as universal as under UI. Approximately 97 percent of the non-federal UI covered workforce is covered, plus all federal employees. Unlike UI, a worker is eligible for WC benefits immediately when she starts work, even without a previous earnings history.

State WC programs cover the medical costs of a work-related injury or illness as well as four main types of cash benefits (also called indemnity benefits). First, 'temporary total' benefits are paid to workers who are totally unable to work for a finite period of time. All workers' compensation claims are initially classified as temporary total cases and temporary total benefits are paid; if the disability persists beyond the date of maximum medical improvement, the case is reclassified as a permanent disability. ${ }^{25}$ About 70 percent of all claims are for temporary total disabilities. Second, if a worker remains totally disabled after reaching maximum medical improvement, she is eligible for 'permanent total' benefits. In most states, permanent total and temporary total benefits provide the same weekly payment, but in some states there is a limit on cumulative permanent total benefits. Benefits equal a fraction (typically two-thirds) of the worker's pre-disability average weekly wage, subject to a minimum and maximum payment. Figure 2.3, described earlier, displays a typical state benefit schedule. The maximum allowable benefit varies substantially across states, and is often linked to the worker's number of dependents. Approximately half of workers earned a high-enough wage that if they incurred a temporary total disability their benefit would be limited by the maximum level in their state. Third, workers who suffer a disability that is partially disabling but is expected to last indefinitely

\footnotetext{
${ }^{25}$ The date of maximum medical improvement is the time at which a doctor determines that an injured worker will not recover further from an injury.
} 
qualify for 'permanent partial' benefits. An employee who loses the use of a limb, for example, would receive permanent partial benefits. These benefits are typically determined on the basis of a schedule that links benefits to specific impairments. For example, an employee who lost the use of an arm in a work-related accident in Illinois in 2000 was entitled to a maximum benefit of $\$ 269,943$. Finally, dependents of workers who are killed on the job are paid survivors' benefits.

Each state law requires a waiting period ranging from three to seven days before indemnity benefit payments begin. However, workers are compensated retroactively for the waiting period if their disability persists beyond a specified time period. Table 3.1 illustrates the interstate variation in workers' compensation benefit minima, maxima, replacement rates, waiting periods, and retroactive periods for twelve states. Comparing this table to Table 2.1, one will notice that $\mathrm{WC}$ has much higher replacement rates and maximum benefits than UI. A typical state has a WC replacement rate of two thirds, but a UI replacement rate of just over onehalf. The typical state has a maximum WC benefit nearly twice that of its maximum UI benefit. Furthermore, workers' compensation benefits are not subject to income or payroll taxes.

The high replacement rates combined with the exclusion of WC from income taxation often leads to after-tax replacement rates near or above one. A couple of representative examples illustrate this point. Suppose an individual's taxable family income was under $\$ 43,850$ in 2000 and she was subject to a 5 percent state income tax. Then, the combination of state income, federal income, and OASDHI payroll taxes implied a 27.65 percent total marginal tax rate. For someone whose benefit was not limited by the maximum benefit and who had a pre-tax replacement rate of two-thirds, the after-tax replacement rate was 92 percent. If income was over $\$ 43,850$, the family was in a higher federal income tax bracket with a total marginal tax rate 
of 40.65 percent and the implied after-tax replacement rate was 112 percent. When a worker has higher take home pay not working than working, there is a strong disincentive to work.

These sharp work disincentives also apply to those who were working full-time, but are considering part-time or temporary work after their injury, likely leading a fifth type of benefits, 'temporary partial benefits,' to be uncommon. A WC recipient with low earnings upon reemployment typically loses two dollars in benefits for every three dollars earned. Given that WC is not subject to income or payroll taxes, the return to working part-time or at a much lower wage than previously earned is negligible or even negative.

\subsection{Workers' Compensation Financing}

Workers' Compensation is mostly financed through insurance premiums paid by firms. WC experience rating is much tighter than UI experience rating, with large firms almost perfectly experience rated. The premium rates as a fraction of payroll range from .1 percent in banking to over 20 percent in construction and trucking in some states. To determine its premium, a firm is placed in one or more of 600 classifications that are a mixture of industry and occupation codes. These classifications determine manual rates, which when multiplied by payroll, give the premium for a small firm. A large firm's rate is a weighted average of the manual rate and the firm's incurred loss rate, typically over a 3 year period in the past. The weight put on the firm's incurred loss rate increases with firm size, with the weight equaling one for very large firms. 


\subsection{Comparisons of UI and WC Program Costs in the U.S.}

Some striking patterns are evident in Table 3.2, which reports aggregate benefits and revenues for UI and WC during the past twenty years. The cyclicality of UI benefit payments is pronounced, with benefit payments high in 1982-1983 and 1992-1993 in response to the downturns near the beginning of those periods. Any cyclicality is less apparent for WC, but a secular rise in WC benefit payments and costs followed by a decline after 1993 is evident. Why WC costs rose so quickly and then fell is only partly understood. The rise was likely associated with benefit increases and associated behavioral responses, as well as the rise in medical costs, while the recent fall is partly due to a decline in injury rates.

\subsection{Workers' Compensation Outside of the U.S.}

We should emphasize that there are often very different institutions in other countries to compensate those injured on the job. Moreover, programs for the injured are often combined with other programs, and those eligible for one type of benefit are often eligible for another in certain circumstances. In particular, there is often no easy translation from the U.S. workers' compensation program to an equivalent in another country, since the U.S. lacks national health insurance and WC provides medical benefits.

In Canada, WC is fairly similar to the U.S, with substantial variation in programs across provinces. Replacement rates are typically 90 percent of earnings net of income taxes, pension contributions, and UI contributions. The waiting period and retroactive period are typically just 
one day, and firms in most cases must purchase insurance through a provincial fund.

In the United Kingdom, those who suffer an industrial accident or contract an industrial disease are generally eligible for the Industrial injuries disablement benefit (IIDB), about half of whom also receive an additional allowance for reduced earnings. These benefits vary with the degree of disablement, but do not vary with previous earnings. The benefits are capped at a low level: IIDB benefits in 2000 were a maximum of $£ 109.30$ (\$161) per week. As a result, these benefits provide little insurance to middle and upper income workers in the U.K. The program appears to be more of a backstop akin to U.S. welfare programs, and expenditures are fairly modest.

\subsection{Theoretical Responses of Labor Supply to Workers' Compensation}

Workers' compensation affects at least four dimensions of labor supply. First, WC can affect the likelihood of an on-the-job injury. Much research on the labor supply effects of WC has focused on this issue. Second, program characteristics affect the likelihood that workers will make a claim given an injury. Once a claim has been made, we expect that labor supply will be affected by the adverse incentives of WC. Third, once on the program, WC can extend the time a person is out of work. Finally, the availability of compensation for on the job injuries can shift labor supply by changing the value to a worker of various jobs. We discuss these four effects in turn.

There is an extensive literature on how the provision of benefits can possibly make the occurrence of an injury more likely. This research is motivated by the idea that workers' (and 
firms) will take fewer actions to prevent an injury when the injury becomes less costly due to the availability of benefits that compensate workers. Krueger (1990) provides a simple model of this situation. Let expected utility on the job be written as

\section{(3.1) $\mathrm{E}[\mathrm{U}]=[1-\mathrm{p}(\mathrm{e})] \mathrm{U}(\mathrm{W})+\mathrm{p}(\mathrm{e}) \mathrm{V}(\mathrm{B})-\mathrm{e}$,}

where e is the workers' effort devoted to injury prevention (care taken, or use of ear plugs, etc). $\mathrm{U}(\mathrm{W})$ is utility when working at wage $\mathrm{W}$, and $\mathrm{V}(\mathrm{B})$ is the utility of the $\mathrm{WC}$ benefit $\mathrm{B}$ when injured. The first-order condition for the choice of e that maximizes utility, assuming an interior solution, is

(3.2) $\mathrm{p}^{\prime}(\mathrm{e})[\mathrm{V}(\mathrm{B})-\mathrm{U}(\mathrm{W})]-1=0$.

By differentiating (3.2) and using the second-order condition, one can show that

(3.3) $\partial \mathrm{e} / \partial \mathrm{B}=\mathrm{p}^{\prime} \mathrm{V}^{\prime} / \mathrm{p}^{\prime \prime}(\mathrm{U}-\mathrm{V})<0$, assuming $\mathrm{p}^{\prime}<0, \mathrm{p}^{\prime \prime}>0$, and $\mathrm{U}-\mathrm{V}>0$.

Thus, the provision of workers' compensation benefits may reduce effort at injury reduction (a dimension of labor supply) and increases the probability of an injury. On the other hand, we should note that more generous WC benefits could decrease injuries through its effect on firm incentives, as discussed by Ruser (1985) and Ehrenberg (1988).

Second, the generosity of WC benefits may affect the probability that a person claims 
benefits conditional on having an injury. As the generosity of benefits rises, it is more likely that the benefits of receiving WC will outweigh the costs, which consist of lost earnings plus the transaction costs of establishing eligibility and possibly the stigma of WC receipt. As a result of higher benefits, there may also be more claims in marginal cases where it is unclear whether the injury is work related and more cases involving outright fraud. ${ }^{26}$ Furthermore, whether someone initially receives WC is partly related to how long they are out of work. A WC claimant cannot receive benefits until after a waiting period of typically 3 days. It is more likely that an injured worker will be out of work longer than this waiting period when benefits are high. Once a person is then on the WC rolls, they become subject to the implicit taxes on work and the consequent work disincentives. Therefore, additional claims will lead to a labor supply response as well as higher costs.

Third, the duration of time out of work is affected by WC. Like UI, this issue is one on which a substantial part of WC research has focused. The duration of time out of work while receiving WC can be thought of as determined by a sequence of decisions. Each period following an injury, an individual compares the benefits received from WC (and the leisure time when not working) to the earnings received when working. A worker's decision would also reflect the disutility of working with an injury (which would tend to fall as an individual recovers) and the increase in productivity with recovery. An additional factor in a person's decision is that a longer stay out of work might facilitate a full recovery, reducing future pain and increasing future productivity. In this setting, higher WC benefits would tend to delay a return to

${ }^{26}$ For anecdotal evidence that higher benefits may also lead to fraud and overstated claims see the New York Times, December 29, 1991, p. 1. 
work, but make a full recovery more likely, just as higher UI could lead to a better job match.

One should note that permanent benefits under WC have an income effect, but no substitution effect. Permanent partial benefits, which are frequently paid as a lump sum settlement, also do not affect the marginal incentives to return to work; they only reduce work by increasing income.

One additional labor supply response is the extent to which labor supply shifts out in response to $\mathrm{WC}$ benefits because they make employment more attractive. This issue is examined theoretically and empirically in Gruber and Krueger (1991). ${ }^{27}$

\subsection{Empirical Evidence on WC Labor Supply}

There are excellent surveys that include summaries of the labor supply effects of WC, such as Ehrenberg (1988), Krueger (1989), Moore and Viscusi (1990), and Kniesner and Leeth (1995). The empirical research on the labor supply effects of workers' compensation, while extensive, is probably less developed than the research on UI. Furthermore, while European researchers have recently produced many convincing studies of UI, research on WC outside the U.S. has lagged.

\subsubsection{The Incidence of Injuries and Workers' Compensation Claims}

Table 3.3 summarizes a large number of studies that examine the effect of workers' compensation program parameters on the incidence of injuries or the incidence of WC claims.

\footnotetext{
${ }^{27}$ Also see Holmlund (1983).
} 
Most of these studies, especially the early ones, examine aggregate data at the state-by-year level, or industry by state-by-year level. These studies tend to find that more generous $\mathrm{WC}$ is associated with higher injury rates, but the effect is usually small. This may be an accurate estimate or a result of the use of aggregate variables and proxies that are required when researchers use state or state by industry data. These studies also tend to find higher claims elasticities than injury elasticities, a result that is expected given the additional effect of higher benefits on claims conditional on an injury. The estimated benefit elasticities cluster around 0.2 or 0.3, though the only studies that use individual microdata, Krueger (1990) and Butler, Gardner and Gardner (1997), find appreciably larger elasticities of the claims rate with respect to benefits. There is also a short literature examining whether claims for hard to diagnose injuries and injuries for which treatment can be delayed are more common when benefits are higher and on days when the injury is more likely a non-work injury (such as Mondays). The evidence on these issues is quite mixed. ${ }^{28}$

\subsubsection{The Duration of Time Out of Work After an Injury}

Most work on incentive effects of workers' compensation has focused on the program's effect on injury rates or the number of claims rather than the duration of claims. However, there has been a great deal of recent research on the effects of WC on the duration of time out of work that we summarize in Table 3.4. Early work by Butler and Worrall (1985) examined low-back injuries in Illinois. They found elasticities between 0.2 and 0.4 , depending on the statistical

\footnotetext{
${ }^{28}$ See Smith (1990), Card and McCall (1996) and Ruser (1998).
} 
technique used. When they examined data pooled from 13 states, however, they did not find a consistent relationship between the level of benefits and the length of spells.

Meyer, Viscusi and Durbin (1995) examined data from a natural experiment provided by two very large increases in benefit levels in Kentucky and Michigan. This natural experiment enables them to compare the behavior of people who are injured before the benefit increases to those injured after the increases. By using the approach outlined in Section 2.5.1., the paper provides a test of the effect of benefit changes on the duration of claims where the sources of identification are readily apparent. Meyer, Viscusi and Durbin (1995) find that a 60 percent increase in the benefit level is associated with an increase in spell duration of approximately 20 percent. The elasticities range from .27 to .62 , with most clustering between .3 and .4 . Overall, the elasticity estimates are very similar in the two states. These results suggest substantial labor supply effects of workers' compensation benefits. Subsequent papers which have followed this natural experiment approach and examined the effects of benefit increases have found large effects. Krueger (1990), Gardner (1991) and the Curington (1994) results for severe impairments all imply duration elasticities over 0.7 . On the other hand, the minor impairment results in Curington (1994) and the recent work of Neuhauser and Raphael (2001) suggest smaller effects, though that latter paper argues that the elasticities are understated due to claim composition changes.

Again, note that the elasticity of lost work time with respect to benefits is the sum of the injury or claims elasticity and the duration elasticity as we indicated in Section 2.5.3. Combining the injury or claims elasticity estimates with the duration elasticity estimates suggests an elasticity of lost work time with respect to WC benefits of between .5 and 1.0. This elasticity is 
probably slightly smaller than the UI elasticity, but implies large effects on work time.

\subsubsection{Other Labor Supply Effects of Workers' Compensation}

Gruber and Krueger (1991) examine the extent to which WC makes employment more attractive for those currently not receiving benefits, leading labor supply to shift out. They find a substantial shift in their study, concluding that workers value a dollar of WC benefits at about a dollar. This increase in labor supply may dampen the labor supply reductions of WC, particularly for high injury jobs that would otherwise be less desirable.

\section{Social Security Retirement Program}

The Social Security system in the United States originated during the New Deal in the 1930s. Old Age Insurance, which in 1939 became Old Age and Survivors Insurance, is now the largest source of retirement income in the United States. Disability Insurance was added in 1956 and Medicare (HI) was added in 1965. In 1998, 90 percent of those age 65 or older received OASDI benefits. ${ }^{29}$ For 18 percent of beneficiary families, Social Security was the sole source of income, and for 63 percent of families it was responsible for more than half of family income. Social Security benefits accounted for 38 percent of aggregate income of the elderly population in 1998 -- nearly twice as much as labor earnings. The poverty rate among older individuals has fallen substantially since the advent of Social Security; in 1998 only 9 percent of beneficiaries

\footnotetext{
${ }^{29}$ The statistics in this paragraph are from Social Security Administration (2000).
} 
were in poverty. Excluding Social Security income, an additional 39 percent of beneficiaries would have income below the poverty line. It would be surprising if a program of this magnitude did not have a substantial impact on the economy.

Social Security can affect labor supply in a myriad of ways. First, and most obviously, by providing benefits to eligible workers after the age of 62 , the program has a "wealth effect" which induces some individuals to retire. Unanticipated increases in benefits that are granted close to retirement age -- which were common when Congress adjusted benefits on an ad hoc basis -- would be expected to have a particularly large effect on retirement because individuals would not have adjusted their earlier consumption and work plans. Second, because the benefit formula specifies greater benefits for those who delay retirement from age 62 to age 70 , the program could induce (or discourage) some workers to remain employed longer than otherwise would be the case. The actuarial non-neutrality of benefits associated with retiring at different ages has changed over time. Third, the program is financed by a pay-as-you-go payroll tax on the working population which would be expected to affect labor supply, although in an ambiguous direction, through traditional income and substitution effects, or through an "entitlement effect" resulting from the prospect of becoming eligible for benefits. In 2000 the OASDHI tax was 7.65 percent of earnings for both employees and employers -- a combined tax rate of 15.3 percent. The OASDI tax applied to the first $\$ 76,2000$ of annual earnings, while the Medicare component of the tax (1.45 percent) is not capped. Most workers pay more in Social Security payroll taxes than they do in federal income taxes. ${ }^{30}$

Social Security can have other, less obvious, but important impacts on labor supply as

\footnotetext{
${ }^{30}$ This statement assumes that employees bear the incidence of the payroll tax.
} 
well. For example, benefits for spouses are set to half of the primary earner's primary insurance amount, unless the spouse's benefits are higher on his or her own account. Thus, Social Security could reduce the incentive for spouses to join the labor force. In addition, Social Security can affect the incentive for partial employment after individuals begin receiving benefits. The Social Security "earnings test" reduces current benefits for beneficiaries whose earnings exceed a threshold level after they begin receiving benefits, although benefits are increased subsequently to compensate. Finally, because only 40 quarters of covered employment are required to become eligible for Social Security, and because the Social Security benefit formula is progressive, Social Security can influence the incentive of individuals to "double dip" -- that is, move from the uncovered to the covered sector -- toward the end of their career. ${ }^{31}$ Moreover, the progressive benefit formula could possibly increase the likelihood that some individuals accept jobs with relatively high nonpecuniary compensation.

Most of the research on Social Security and labor supply has focused on the first two effects outlined above -- the wealth effect and the substitution effect caused by benefits depending on retirement age. In addition, a recent thrust of research has focused on the impact of the earnings test.

Some have attributed the long-term downward trend in labor force participation among older men to the availability of Social Security and Disability Insurance. This conclusion,

${ }^{31}$ The expansion of mandatory coverage to the public sector, self-employed sector, and non-profit sector over time reduced the incentive for double dipping. Workers currently excluded from coverage mainly include: federal civilian employees hired before January 1, 1984; railroad workers; employees of state and local governments who are covered under a retirement system; and household workers, self-employed workers and farm workers with very low earnings. 
however, hinges on what the labor force participation rate would have been in the absence of Social Security. Such a counterfactual is suggested, in large part, by the labor force participation trend prior to the advent of Social Security in 1935. Perhaps the post-1935 downward trend is just the continuation of a pre-existing trend. The data in Figure 2 suggest that labor force participation declined steadily throughout the 20th Century, including the pre-Social Security era. Using a different definition of labor force participation, however, Ransom and Sutch (1986) find that the labor force participation rate of men age 60 or older was fairly stable in years prior to the start of Social Security. Costa (1998), Lee (1998) and Margo (1993) question the historical data used by Ransom and Sutch. ${ }^{32}$ In any event, attributing causality depends on the counterfactual trend in labor force participation in the absence of Social Security. It is possible that labor force participation would have declined more slowly in the post 1935 period absent Social Security, regardless of whether it was declining prior to 1935. The historical data, though interesting, are unlikely to shed compelling evidence on the impact of Social Security on labor force participation.

Table 4.1 summarizes several studies of the effect of Social Security on labor supply. The set of studies reviewed in the table is not exhaustive; rather, studies were selected because they illustrate a particular approach to the problem and/or because they have been particularly influential. Studies of the impact of Social Security on labor supply can be divided into two types. One group relies primarily on time-series variation in the law to identify the effect of changes in benefit levels or other parameters of the Social Security system on labor supply. The

\footnotetext{
${ }^{32}$ Ransom and Sutch assume that anyone who is unemployed for 6 months or more in 1900 is out of the labor force.
} 
other group relies on cross-sectional variation in benefits (i.e., differences across workers at a point in time) to identify the effect. Studies that analyze longitudinal data are a hybrid, potentially drawing on both time-series and cross-sectional variation in benefits.

In one of the more influential papers in the literature, Hurd and Boskin (1984) estimate the effect of Social Security wealth on retirement using longitudinal data on men age 58 to 67 from the Retirement History Survey. They model retirement in the years 1969, 1971 and 1973, and report many alternative ways of measuring the impact of Social Security on labor supply. Cross tabulations of retirement rates by age, assets, and Social Security wealth indicate: (1) a large increase in the retirement rate at age 62, when individuals become eligible to receive Social Security benefits; and (2) a higher retirement rate for those who would qualify for greater Social Security benefits.

They also provide a series of logistic estimates of the probability of retiring at a given age. Their Social Security wealth variable corresponds to the present value of benefits that the individual would receive if he retired in that year, given his earnings history, family status, life expectancy, and the prevailing Social Security law at that time. Although they use panel data and study a period during which benefits were rising rapidly, variation in benefits is primarily a result of cross-sectional differences in individual circumstances because they control for cohort effects and estimate separate models by age (which has the effect of absorbing any time-related variable that cuts across individuals). Their estimates imply that a $\$ 10,000$ increase in Social Security wealth (in 1969 dollars) is associated with an increase in the retirement rate of 7.8 percentage points. Hurd and Boskin further predict that, based on this cross-sectional estimate, the 52 percent increase in Social Security benefits between 1968 to 1972 would lead to a decline in 
labor force participation of older men of 8.4 percentage points. This slightly exceeds the actual decline of 8.2 points. If this conclusion is correct, then Social Security has had a major impact on the decline in male labor supply.

Studies that examine cross-sectional data -- or exploit cross-sectional variability in benefits in panel data by absorbing time effects -- necessarily estimate how the prevailing Social Security law in a given year influences behavior (examples include Hurd and Boskin, 1984, Boskin, 1977, and Pellechio, 1979 and 1981). Moffit (1987; p. 185) raises a fundamental concern about the econometric identification of Social Security effects in such studies:

For social security, the law is the same for all people at any given time; consequently, all cross-sectional variation in social security benefits or any other measure of the system must arise from cross-sectional variation in earnings received over the lifetime, in family size and the number of dependents, in maritial status, and in other such variables.

That is, there is no variation in the law itself. The potential difficulty of course is that the variables for which variation is available may have independent effects on labor supply; hence there is a fundamental identification problem in cross-sectional data, a problem that can only be overcome by making restrictions in functional form of one kind or another.

Consequently, the impact of Social Security can only be untangled from the impact of other variables if functional form and exclusion assumptions are made, such as the assumption that marital status or past earnings do not directly influence labor supply. ${ }^{33}$ In many cases, these assumptions are untenable. For example, if one considers two workers who qualify for different Social Security benefits because one of the workers earned higher earnings throughout his career by dint of hard work, motivation and innate talent, it is difficult to believe that those very characteristics would not influence the likelihood that the workers would retire at different ages,

\footnotetext{
${ }^{33}$ Quinn (1987) makes a similar point.
} 
apart from their Social Security wealth. In this situation, the Social Security wealth variable would confound the effect of one's past earnings history on labor supply and the effect of Social Security wealth on labor supply. Notice, however, that conditional on earnings or non-SocialSecurity wealth, in all likelihood the worker with history of higher earnings has lower Social Security wealth because the benefit formula is progressive. That is, the positive unconditional relationship between Social Security wealth and past earnings is reversed if one conditions on past earnings, or uses the replacement rate as a measure of benefit generosity. Therefore, the estimates will be highly sensitive to the other variables included in the equation.

Panel data that follow individuals over time and time-series data provide a means to allow changes in the Social Security law to influence the benefits that individuals receive. The difficulty here, however, is that variables often trend together. Many of the papers that rely on time-series variation in benefits, for example, are based on the Retirement History Survey, which follows individuals over the years 1969-1979 (examples are Hurd and Boskin, 1984; Burtless, 1986; and Anderson, Burkhauser, and Quinn, 1986). During these years Social Security benefits grew rapidly owing to ad hoc changes to the Social Security Act and the over indexation of benefits. Most of the analyses of data from this time period conclude that more generous Social Security benefits reduce labor force participation, induce earlier retirement, or induce individuals to retire earlier than they had previously planned. But the negative association between Social Security wealth and labor supply in these studies may spuriously reflect the coincidence of two trends: rising benefits and falling labor supply, which were due to unrelated causes. Indeed, the long-term time-series studies mentioned previously (see Figure 2), and Moffitt's (1987) cohort-level study of labor supply in the years 1955-1981 suggest that the timing 
of the decline in labor supply does not correspond well with changes in Social Security wealth. These results suggest that estimates that are identified by continually rising benefits over time may reflect secular time trends in labor force withdrawl, rather than a response to Social Security. Krueger and Pischke (1992) seek to avoid this problem by examining cohort-level data for a period in which benefits rose and then fell for succeeding cohorts. Specifically, because benefits were over indexed for inflation in the 1970s and then corrected abruptly by legislation passed in 1977 for cohorts born between 1917 and 1921, the so called Notch Babies, there were large, unanticipated differences in benefits for otherwise identical individuals depending on whether they were born before or after 1917. This situation creates a natural experiment that can be used to identify the effect of Social Security wealth apart from general time trends. Figure 4.1 summarizes Krueger and Pischke's main findings. They used March CPS data from 1976 to 1988 to create a panel of labor force participation rates by single year of age for men aged 60-68. Social Security wealth was calculated for a man with average earnings in each birth cohort at each age and year. The data reported in the figure are the average labor force participation rate and Social Security wealth for each cohort, after removing age effects from both series. Benefits exhibit a sharp zig-zag pattern as a result of over indexation and the subsequent correction for the notch cohort. Labor force participation, however, displays a steady downward trend, which is largely unrelated to the sharp movements in Social Security wealth. ${ }^{34}$ Logistic regressions that control for other variables, including the growth in Social Security wealth that is associated with delayed retirement, yield a similar conclusion: labor force participation rates of older men are

\footnotetext{
${ }^{34}$ Peracchi and Welch (1994) who also analyze CPS data, reach a similar conclusion concerning trends in labor force participation of older men, although they do not directly measure Social Security benefits.
} 
unrelated to movements in Social Security wealth generated by the benefit notch.

There is considerable disagreement in the literature as to the magnitude and direction of the effect of Social Security on labor supply. For instance, after reviewing the past literature Aaron (1982) concludes there is little evidence showing Social Security has reduced the labor supply of elderly workers, whereas Boskin (1986; p. 62) concludes, "the acceleration in the decline of the labor force participation of the elderly from 1969 to 1973 was primarily due to the large increase in real Social Security benefits." Anderson, Gustman and Steinmeier (1999). Quinn, Burkhauser, and Myers (1990), Hurd (1990), Ippolito (1988), Parnes (1988) and Danziger, Haveman, and Plotnick (1981) reach more of a middle-ground conclusion, attributing a portion of the observed decline in labor force participation of older workers to Social Security. In our opinion, studies that use a more plausible identification strategy -- for example, using variability in benefits due to legislated changes that cause breaks in the steady trend toward more generosity benefits -- tend to find a very modest impact of Social Security wealth on labor supply in the United States.

Evidence from other countries is also mixed. For example, Baker and Benjamin (1999) find that the introduction of early retirement benefits in Quebec in 1984 led to significant increases in participation in the pension program for men age 60-64, but no greater increase in early retirement than that found in the rest of Canada, which adopted early retirement benefits later. This finding suggests that men who participated in the early retirement pension program would have retired anyway, and serves as a useful reminder that just because there is take-up of benefits in a social insurance program, the program may not affect behavior. On the other hand, the studies in Gruber and Wise (1999) suggest that Social Security systems have contributed to 
labor force withdrawal in many countries, particularly in Germany and France.

\subsection{Automatic Benefit Recomputation}

When a worker delays retirement after becoming eligible for Social Security, his or her Social Security wealth changes. Benefits are automatically recalculated to reflect the worker's current experience. Social Security wealth changes because: (1) the worker typically displaces a year of low earnings with a year of high earnings, which raises the primary insurance amount, as emphasized by Blinder, Gordon and Wise (1980); (2) the worker grows older and therefore has less expected time left to collect benefits; (3) the actuarial adjustment to benefits may or may not be fair. ${ }^{35}$ Moreover, because workers can self-select their retirement age based in part on their expected life expectancy, an actuarial adjustment to benefits based on unconditional lifetables is likely to be favorable to workers.

As Blinder, Gordon and Wise (1980) have noted, the ad hoc changes in Social Security benefits enacted by Congress prior to 1975 and double indexation typically resulted in more than actuarially fair growth in Social Security wealth for workers under 65 years old who postponed their retirement. They also noted that the 1977 amendments to the Social Security Act would substantially reduce the relative wealth advantage of delaying retirement. As a consequence, prior to the 1977 ammendments, one would expect the Automatic Benefit Recomputation to induce some workers to delay their retirement. Krueger and Pischke (1992) report some

\footnotetext{
${ }^{35}$ The first factor has less of an effect currently because a worker's past earnings are now indexed to overall earnings growth in the calculation of benefits.
} 
evidence of this effect.

\subsection{Liquidity constraints}

Perhaps the most noticeable feature of retirement behavior is that a high proportion of people tend to retire immediately upon turning age 62 or age 65 . Figure 4.2, taken from Rust and Phelan (1997), illustrates the spike in the retirement rate at ages 62 and 65. Using data on men from the Retirement History Survey, the figure shows the fraction of workers who begin receiving Social Security benefits at various ages. Nearly a quarter of workers first receive Social Security benefits in the year they turn 62, the very first year they are eligible, and almost as many start to receive benefits in the year they turn 65 , the "normal" retirement age. A number of authors, including Crawford and Lilien (1981), Hurd and Boskin (1984), Boskin (1977), Kahn (1988), and Rust and Phelan (1997) have concluded that the jump in the retirement rate at age 62 is a result of liquidity constraints. That is, workers cannot borrow against their future Social Security wealth and many lack access to other forms of credit, so they wait until age 62 to receive retirement benefits, even though they would prefer to retire earlier and borrow to finance their consumption.

Rust and Phelan (1997) provide a dynamic programming model of the retirement decision, specifically modeling the effects of Social Security in a world with incomplete markets for loans, annuities and health insurance. Their simulation results suggest that liquidity constraints can account for the spike in retirement at age 62. During the period they studied, the actuarial adjustment for delaying retirement beyond age 65 was unfair -- which would have 
encouraged workers to retire at age 65 -- but they conclude that the actuarial penalty for working longer only partially explains the spike in retirement at age 65. More importantly, they suggest that eligibility for Medicare is the main reason for the spike at age 65. That is, workers become eligible for Medicare at age 65, so the value of employer-provided health insurance drops discretely at this point. Interestingly, they find that workers who have employer-provided health insurance but no access to retiree health insurance are four times more likely to retire at age 65 than are those who lack health insurance or have coverage independent of employment. And workers who lack health insurance or have coverage independent of employment are much more likely to retire at age 62 than are those who rely on employer-provided coverage. Thus, they find evidence that the spike in the retirement rate at age 65 is largely due to "health insurance constrained" individuals. ${ }^{36}$

Two additional factors might contribute to the discrete jump in the retirement rate at age 65. First, many private pensions penalize workers who continue working after age 65 . Second, until 1978, the United States permitted companies to maintain mandatory retirement policies, which enabled them to mandatorily retire workers upon reaching age 65 . The mandatory retirement age was lifted to 70 in 1978, and then eliminated for most occupations in 1987.

A test of the impact of the Social Security program on the jump in the retirement rate for 65 year olds will soon be possible. In 1983 the Congress approved legislation that will gradually raise the normal retirement age from 65 to 67 . The normal retirement age will rise by two months a year from 2003 through 2008, and then after a 12 year pause, it will rise again by two

${ }^{36}$ See Gruber and Madrian (1995) for related evidence showing that the likelihood of retirement is higher for older workers in states that mandate that individuals have the right to purchase health insurance from a previous employer after leaving the firm. 
months a year from 2020 through 2025. It will be interesting to see if the retirement spike moves up by two months a year along with the normal retirement age, especially because the age of eligibility for Medicare will not increase with the normal Social Security retirement age. This program change should provide fertile research ground in the future.

\subsection{Earnings Test}

Since it was founded, Social Security has included some form of a retirement earnings test, intended to limit benefits to retired individuals. Under the earnings test, Social Security recipients who have labor earnings in excess of a certain threshold lose part or all of their benefits in the year of their earnings. The particulars of the earnings test have varied considerably over time. The original Social Security Act of 1935 required that no benefits be paid to beneficiaries who received earnings from regular employment. Before it was repealed, in 2000 beneficiaries under the age of 65 could earn up to $\$ 10,080$ without any benefit offset, but benefits were reduced by $\$ 1$ for every $\$ 2$ of earnings above that threshold. The earnings test was less stringent for beneficiaries age 65 to 69 : in 2000 they were allowed to earn up to $\$ 17,000$ without a benefit offset, and then faced a $\$ 1$ reduction in benefits for every $\$ 3$ of earnings above that threshold. ${ }^{37}$ Since 1983 , beneficiaries age 70 and older have not been subject to an earnings test.

A delayed retirement credit was provided to compensate workers age 65 to 69 whose

${ }^{37}$ To be more precise, the lower age level pertained to people age 65 in the calendar year in which they turned 65 . 
benefits were offset by the earnings test. The delayed retirement credit increased workers' retirement benefits by 6 percent for each full-year-equivalent of benefits that were lost because of the retirement test. The 6 percent increase was not actuarially fair, but it was close to being actuarially fair. Similarly, beneficiaries age 62 to 65 who lost benefits because of the earnings test received an actuarial adjustment to their benefits later on (at age 65) to compensate for the earnings test.

Legislation passed unanimously by the House and Senate and signed by President Clinton in April 2000 eliminated the earnings test for workers age 65-69. For benefit computation, the earnings test was repealed retroactively to the beginning of the calendar year. The earnings test remained in place for younger beneficiaries, however. Because of the delayed retirement credit (which was already almost actuarially neutral, and slated to become actuarially neutral in the near future), the elimination of the earnings test was not expected to increase expenditures in the long run.

Policy makers including Alan Greenspan and Bill Clinton said they expected the elimination of the earnings test to increase labor supply of elderly workers. This argument probably relies more on psychology than economics, because the earnings test had an approximately actuarially neutral effect on workers' Social Security wealth. Nevertheless, if workers who were potentially affected by the earnings test did not realize that their benefits would subsequently be increased to compensate for benefit reductions for earnings above the threshold, or if they acted as if they were liquidity constrained or myopic and put greater weight on present benefits than future benefits, then eliminating the earning test is like eliminating a payroll tax. In this case, for workers on the margin of working enough hours to exceed the 
threshold, the elimination of the earnings test would be expected to lead to an increase in labor supply. For workers above the threshold, the elimination of the earnings test in this setting would have opposing income and substitution effects.

Empirical evidence on the labor supply effects of the earning test is mixed, although the strongest evidence suggests that eliminating the earnings test will have at best a modest effect on labor supply. Friedberg (2000) finds evidence suggesting that some workers do respond to the earnings test because the earnings distributions of 63-69 year old workers tend to display excess clustering just below the relevant earnings thresholds. Moreover, the mass in the distribution just below the threshold moves when the threshold moves. It is unclear whether this clustering signifies an important labor supply response, however, because the number of workers who are clustered just below the threshold point is relatively small compared to total labor supply of older workers; the response of workers above the threshold level is potentially of more importance for overall labor supply. Friedberg (2000) estimates the impact of the earnings test on labor supply by estimating the parameters of a labor supply function by maximum likelihood assuming utility maximization over the piecewise linear budget constraint created by the earnings test. She predicts that eliminating the earnings test would raise the aggregate work hours of 65-69 year old men by 5 percent. Friedberg's estimates imply a larger labor supply response than most of the rest of the literature on the earnings test.

Gruber and Orszag (2000), for example, examine the impact of past changes in the earnings test on the labor supply behavior of elderly men and women in a less structural way. They directly examined how various measures of labor supply of older workers changed in years when parameters of the earnings test changed between 1973 and 1998. Specifically, they use 
data on the previous year's earnings, hours worked, employment status, and Social Security receipt of men and women age 59 to 75 from March Current Population Surveys conducted from 1974 through 1999. They conclude that the earnings test exerts no robust influence on the labor supply decisions of men, although they find some evidence of an effect for women. The apparently weak impact of the earnings test on labor supply is probably more a result of a relatively inelastic labor supply response to a perceived tax, than a result of a rational calculation by the elderly that the discounted actuarial present value of their benefits is unaffected by their labor supply.

An obvious direction for future research is to use the elimination of the earnings test for 65-69 year olds that was enacted in 2000 to test the impact of the earnings test on labor supply behavior. For example, changes in the aggregate hours worked by $65-69$ year olds before and after 2000 can be compared to the corresponding changes for 62-64 year olds and 70-74 year olds to control for business cycle effects. It is rare that economists can examine the effect of such a large and sudden change in a program parameter.

\section{Disability Insurance}

To qualify for the Disability Insurance program, insured individuals must be unable "to engage in substantial gainful activity, by reason of a medically determinable physical or mental impairment that is expected to result in death or last at least 12 months." There is also a fivemonth waiting period before an applicant to DI can start receiving benefits. This is a strict standard. In essence, applicants must be unable to work in any job that exists in the U.S. 
economy. The Social Security Administration advises prospective applicants: "If you cannot do the work you did in the past, we see if you are able to adjust to other work. ... If you can adjust to other work, your claim will be denied." ${ }^{38}$ To qualify as covered for disability insurance, individuals age 31 or older must fully meet the insurance coverage requirements under Social Security and have worked in covered employment in at least 20 of the last 40 calendar quarters. The coverage requirement is less stringent for individuals younger than 31 because they have less time to satisfy the Social Security eligibility requirements. ${ }^{39}$

A worker who qualifies for DI before reaching the normal Social Security retirement age can receive a benefit equal to 100 percent of his or her primary insurance amount. The spouse and unmarried children (under the age of 18 , or 19 in the case of full-time students) of a disabled worker can also qualify for benefits. There is a cap on the total amount of benefits a family can receive, however. ${ }^{40}$

Despite the official criteria, it is important to bear in mind that the assessment of a disability is inherently a subjective decision. ${ }^{41}$ As Bound and Waidman (2001) stress, the standards used to evaluate whether individuals meet the DI disability test have varied over time, and are a major determinant of the number of participants on the DI program. For example, in

\footnotetext{
${ }^{38}$ See http://www.ssa.gov/dibplan/dqualify6.htm.
}

${ }^{39}$ The blind are exempt from the requirement that they have considerable covered work in recent calendar quarters (i.e., 20 out of the last 40 quarters requirement for workers older than 30). Those who do not meet the employment history requirement for DI can apply for the Supplemental Security Income program, which pays less generous benefits but has no past employment requirement.

${ }^{40}$ For program details, see Rejda (1999) or Bound and Burkhauser (2000).

${ }^{41}$ See Diamond and Sheshinski (1995) for a model of the optimal structure of DI benefits in a world with uncertain and imperfect evaluations of applicants' disability status. 
1980 Congress required more frequent eligibility reviews to check if beneficiaries continued to have a disability. Then in 1984 Congress loosened eligibility requirements, by, among other things, shifting the burden of proof to the Social Security Administration to demonstrate that the beneficiary's health had improved sufficiently to return to work, and placing more weight on the claimant's own medical evidence. In addition, the Social Security Administration changed its treatment of claims involving mental illness, by emphasizing the ability of the claimant to function in work or a work-like environment. As a consequence, by 1988 mental health became the most prevalent disabling condition among new beneficiaries, increasing from 11 percent of all cases in 1982 to 22 percent in 1988, and peaking at 26 percent in $1993 .^{42}$ In 1996 alcoholism and drug addiction were removed as disabling conditions, but mental impairment continues to be the most prevalent disabling condition, accounting for 22 percent of beneficiaries granted benefits in 1999.

Figure 5.1 illustrates the number of disabled workers receiving DI benefits in selected years since 1960. The number of disabled workers on DI was less than 0.5 million in 1960, and then grew rapidly in the 1960 s and 1970 s, reaching 2.9 million in 1980 . The number of beneficiaries fell slightly between 1980 and the mid 1980s, and then began to grow rapidly again beginning in the mid to late 1980s. The steady rise in the number of DI beneficiaries in the 1990s is rather surprising in view of the strong labor demand in the U.S. in that period. The unemployment rate, for example, fell from 7.5 percent in 1992 to below 4 percent at the end of 1999. DI participation usually follows a counter cyclical pattern. ${ }^{43}$ Part of the explanation is

${ }^{42}$ See House Ways and Means Committee, Green Book, 2000, Table 1-43.

${ }^{43}$ See Black, Daniel and Sanders (1998) for compelling evidence that economic conditions influence participation on DI. Using exogenous shocks to local economic conditions 
simply that mortality decreased among the stock of DI recipients (because new recipients had longer life expectancies), which caused the number of people on the rolls to grow (see Autor and Dugan, 2001).

Another curious development is that the employment rate of people with a self-reported disability fell in the 1990s, especially for men. For example, Bound and Waidman (2001) find that the employment rate of 30-44 year old men with a work limitation fell from just over 40 percent in 1990 to below 30 percent in 1999. Employment rates of other workers increased or remained constant over this period. The distinct downward trend in employment for people with disabilities has stimulated new research into the DI program that is described below.

The earliest studies of DI examined the relationship between the generosity of DI benefits and participation in the DI program. ${ }^{44}$ Perhaps best known and most controversial, Parsons (1980) estimated a probit model to explain labor force participation using data on 48 to 62 year old men from the 1969 cross-sectional wave of the National Longitudinal Surveys. ${ }^{45}$ The key independent variable was the ratio of each individual's potential Social Security benefit to his hourly wage three years earlier. The results indicated an elasticity of labor force participation with respect to the potential benefit replacement rate of -.63 , with a t-ratio of -2.5 . The elasticity is even larger in magnitude for those in poor health, as proxied by their subsequent mortality probability. An issue that we have stressed repeatedly in this chapter arises in interpreting these

resulting from swings in the coal industry in four states, they find that the elasticity of DI payments with respect to local earnings is -0.3 to -0.4 . Similar results are obtained when they use shocks due to the collapse of the steel industry in six other states.

${ }^{44}$ See Bound and Burkhauser (2000) for a comprehensive summary of research on many aspects of DI, including labor supply.

${ }^{45}$ See also Leonard's (1979) related study. 
probit estimates: the Social Security benefit is a deterministic function of past labor market behavior, so it is impossible to identify the effect of benefits separately from the effect of past behavior that might be related to present labor supply for reasons having nothing to do with DI. Had a more flexible function of past earnings been included in the model, the effect of the benefit variable would not have been estimable. Indeed, there is an indication that identification of the benefit elasticity apart from the effect of past wages is a problem in this analysis as Parsons reports in a footnote that the replacement ratio was used because of collinearity programs if wages and benefits were entered as separate variables. Because the potential Social Security benefit relative to the wage is lower for those with higher wages or more steady employment, there is a real possibility that the inverse relationship between the replacement rate and labor force participation is merely a reflection of the positive relationship between employment rates and earnings potential.

This problem aside, Parsons (1980) provides a rather useful check on the plausibility of his benefit elasticity. Specifically, he uses the estimated cross-sectional model to predict the labor force nonparticipation rate each year from 1948 to 1976. This is accomplished by combining the cross-sectional parameter estimates with values of the replacement rate and mortality index each year to generate predicted nonparticipation rates. This exercise reveals a fairly tight correspondence between predicted labor force nonparticipation and the actual nonparticipation rate. Because other variables not captured by the cross-sectional model may change over time (e.g., disability assessment standards could change), and the parameters in the cross-sectional model may also change over time, there is no guarantee that the predicted values will closely mirror the observed values, even under the best of circumstances. So this test does 
provide some additional information. (Another way of performing this same type of comparison would be to estimate a nonparticipation rate model with aggregate time-series data, and test if the benefit elasticity is the same as in the cross-sectional model.) It is certainly possible, however, that the similarity of the time trends in the predicted and actual nonparticipation rates is just coincidental, a reflection of rising benefits and declining participation in this period for unrelated reasons. Nevertheless, if the prediction diverged substantially from the actual data, then one would have even more reason to be skeptical of the cross-sectional estimate.

Bound (1991) challenges Parson's conclusion that DI is responsible for the decline in male labor force participation in the post-World War II period. He presents two types of evidence. First, he documents that among prime-age male applicants to DI who were rejected from the program because they were not judged to have a medical disability in 1972 and 1978, less than one half subsequently returned to sustained employment. He argues that the experience of these individuals, who presumably are healthier than DI beneficiaries, provides a natural upper bound estimate for the employment rate of DI beneficiaries had they been denied access to DI. ${ }^{46}$ Because the drop in labor force participation has more than matched the rise in the proportion of older men on DI, he concludes that "DI accounts for substantially less than half of the postwar decline in the participation rates of older men." Second, and related, he estimates a

${ }^{46}$ Parsons (1991) questions whether the employment experiences of denied applicants to DI provide a natural control group for successful applicants, because denied applicants may refrain from working because they are appealing their rejection from the program or plan to reapply to DI and would like to strengthen their case, or because they face obstacles returning to work because they spent time out of the labor force while applying to DI. In other words, in the absence of the program their employment rates might be higher. Similar arguments could be applied to Bound's logit equation described below. See Bound (1991) for a reply to this critique. 
nonemployment logit equation similar to the nonparticipation equation in Parsons (1980), except he uses a sample of individuals who never applied to DI, as well as a sample that closely parallels the one used by Parsons. The estimated elasticity of nonemployment with respect to the benefit replacement rate is similar in both samples. He infers from this that Parsons's estimate of the DI benefit elasticity is biased upwards because the non-applicants could not have been affected by DI. Although Bound acknowledges that DI does influence labor supply incentives, he questions whether the availability of the program is a major reason for the decline in male labor force participation, and he suggests that benefits are well targeted towards those who would not seek employment even in the absence of the program.

More recent studies have sought to explain both the rising number of DI participants and declining employment rate of individuals with self-reported disabilities since the late 1980s. Ironically, this rise in DI participation occurred during a time when the overall employment-topopulation rate increased to a historically high level. Nevertheless, the employment rate fell considerably for male high school dropouts in the 1990s. Moreover, the declining labor force participation of people with disabilities is of concern if individuals with disabilities desire to work, and the expanding DI rolls in a period of strong growth in employment demand raises concerns about possible labor supply disincentive effects caused by the program. Although several hypotheses have been proposed to explain the fall in employment of people with disabilities and the rise in DI participation in the 1990s, a fair assessment is that this is an area where a consensus on the causes of these developments has yet to emerge.

Bound and Waidman (2001) attribute the decline in employment among people with a self-reported work disability mainly to increases in the availability of DI due to changes in 
disability assessment standards. Their evidence is rather circumstantial, however. Looking across states between 1989 and 1999, they find that the change in the fraction of the population that has a work limitation and is out of work tends to increase almost one for one with the proportion of the working-age population on DI. This suggests that many of the self-reported work-limited individuals who left employment received support from the DI program, perhaps because access to DI was relaxed.

Autor and Duggan (2001) attribute the rise in participation in the DI and SSI programs since the mid 1980s to the reduced stringency in screening applicants and to the interaction between growing wage inequality and the progressive benefit formula in these programs. The effective benefit replacement rate increased because the earnings of less-skilled workers fell, and the benefit formula is progressive and linked to average earnings. For example, between 1979 and 1999 the replacement rate increased from 56 percent to 74 percent for a 40-49 year old man at the $10^{\text {th }}$ percentile of the earnings distribution. The addition of Medicare or Medicaid benefits could raise the effective replacement rate above 100 percent. Autor and Duggan also present cross-state evidence showing that the share of the population applying for DI benefits has become more responsive to employment shocks since the early 1980s. Thus, the declining job opportunities for less skilled workers, together with the progressive DI benefit formula and more liberal screening rules, may account for the increased participation in disability programs.

Acemoglu and Angrist (2001) and DeLeire (2000) look at another policy as a possible cause of the decline in labor force participation of those with a self-reported disability, the Americans with Disabilities Act (ADA) of 1990. This Act requires employers to accommodate disabled workers (e.g., by providing physical access) and outlaws discrimination against the 
disabled in hiring, firing, and compensation. Although the ADA was intended to increase employment of the disabled by reducing discrimination and increasing access, it also increases costs for employers. Acemoglu and Angrist, for example, find evidence that the employment of disabled workers declined more in states where there have been more ADA-related discrimination charges. ${ }^{47}$

A final factor may be welfare reform. Even before Aid to Families with Dependent Children was repealed in 1996, states had tightened their welfare laws. It is possible that an increasing number of people sought DI because they were no longer eligible for welfare, or because welfare became less generous. Because state welfare programs primarily affect women, this might also help explain why the relative number of male to female workers who joined the DI rolls increased from 2 to 1 in 1985 to 1.2 to 1 in $1999 .^{48}$ The proportion of women who reported having a health limitation or disability that restricts them from working increased in the 1990s, after declining in the 1980s (see Bound and Waidman, 2001). It is also possible that the changing mores concerning welfare may have affected responses to Census questions on disability status. It seems reasonable to speculate that during the 1990 s because of the stigma associated with welfare it became socially less acceptable for an able bodied individual to report that he or she did not work. So a growing proportion of people who were out of the labor force might have reported a health-related work-limitation as the reason why they did not work because of changes in social norms.

\footnotetext{
${ }^{47}$ Bound and Waidman (2001), on the other hand, point out that the rise in disability applications began in 1989-90, prior to the passage fo the ADA.

${ }^{48}$ House Ways and Means Committee, Green Book, 2000, Table 1-43. The growing labor force participation of women might also help explain the change in the sex ratio of DI participants.
} 


\section{Conclusion}

The empirical work on unemployment insurance and workers' compensation insurance reviewed in this chapter finds that the programs tend to increase the length of time employees spend out of work. Most of the estimates of the elasticities of lost work time that incorporate both the incidence and duration of claims are close to 1.0 for unemployment insurance and between 0.5 and 1.0 for workers' compensation. These elasticities are substantially larger than the labor supply elasticities typically found for men in studies of the effects of wages or taxes on hours of work; such estimates are centered close to zero (see, e.g., Killingsorth, 1983 and Pencavel, 1987). They are also larger than the consensus range of estimates of the labor supply elasticity for women, which is highly dispersed but centered near 0.4 . These seemingly disparate results may, in part, be reconciled by the likelihood that elasticities are larger when a labor supply response can easily occur through participation or weeks worked, rather than adjustments to the number of hours worked per week. Labor supply responses to WC and UI benefits occur mainly through decisions about weeks worked, and labor supply responses of women mainly concern participation and weeks worked. Male labor supply elasticities by contrast are primarily determined by adjustments to hours worked per week, a margin on which employees may have relatively little flexibility. These observations suggest that it would be misleading to apply a universal set of labor supply elasticities to diverse problems and populations.

Temporary total workers' compensation insurance benefits and the UI program also may generate relatively large labor supply responses because these programs lead to only a short-run 
change in the returns to work. For example, individuals are not eligible to receive UI benefits for an indefinite period; there is a maximum number of weeks benefits can be received. Thus, workers may inter-temporally substitute their labor supply while benefits are available, generating larger work responses than predicted by long-run labor supply elasticities. The window of eligibility for Social Security and Disability Insurance benefits is more permanent, so such inter-temporal considerations are likely to be less important.

In addition, receipt of UI and temporary total WC benefits makes the net wage (after-tax wage minus after-tax benefits) very low, often close to zero in the case of WC benefits. This situation is different from a typical cut in wages for two reasons. First, the income effect does not counterbalance the substitution effect to the usual extent because benefits are provided and income often does not fall appreciably. In the case of a replacement rate of 0.8 , for example, the net wage falls by 80 percent, but short-run income falls by only 20 percent. In the usual case of wage variation, a drop in the wage dramatically lowers income, and thus, the income effect tends to mitigate the substitution effect. Second, the level of the net wage may be so low that it is out of the range of typical variation in cross-section wages or wage variation due to taxes. Thus, estimates based on other sources of wage variation may be less applicable to UI and WC.

Despite labor supply responses to social insurance programs, we would emphasize that the desirability of social insurance depends on the intended as well as unintended effects (or, more appropriately put, undesired side effects) of the programs. Thus, a finding of labor supply responses to incentives is not necessarily cause for abandoning a program. The undesired side effects must be balanced against the improved welfare from providing income maintenance to those in need. Moreover, for some programs, such as UI, it is quite likely that the adverse 
incentive effects vary over the business cycle. For example, there is probably less of an efficiency loss from reduced search effort by the unemployed during a recession than during a boom. As a consequence, it may be optimal to expand the generosity of UI during economic downturns (assuming the initial starting level was optimal). Unfortunately, this is an area in which little empirical research is currently available to guide policymakers.

A final point worth highlighting is that less research has been conducted on WC and DI than on UI, despite the large magnitude of the programs. In our view, WC and DI are under researched relative to their importance to the economy and merit further study. These programs exhibit substantial variability over time or across states, and large data sets are available that can be analyzed, so there is potential for many valuable research projects on WC and DI. Another fruitful area for research involves the overlap among programs. For example, individuals who receive both WC and DI benefits have their DI benefits reduced if their combined level exceeds a certain threshold. Little research has been done on the incentive effects caused by the interactions among social insurance programs. Also, while the UI literature for Europe is rapidly catching up to the American literature, relatively little work has been done on WC-like programs outside the U.S. 


\section{REFERENCES}

Aaron, H. J. (1982), Economic effects of social security (Brookings Institution: Washington, D.C.).

Abbring, Jaap H., Gerard J. van den Berg, and Jan C. van Ours (2000), "The Effect of Unemployment Insurance Sanction on the Transition Rate from Unemployment to Employment", Working Paper, Free University, Amsterdam.

Acemoglu, D. and J. Angrist (forthcoming), "Consequences of employment protection? The case of the Americans with Disabilities Act", Journal of Political Economy.

Adams, J. (1986), "Equilibrium Taxation and Experience Rating in a Federal System of Unemployment Insurance", Journal of Public Economics 29:51-77.

Aiuppa, Thomas and James Trieschmann (1998), "Moral Hazard in the French Workers' Compensation System”, Journal of Risk and Insurance. 65(1):125-33.

Anderson, K. H., R. V. Burkhauser, and J. F. Quinn (1986), "Do retirement dreams come true? The effect of unanticipated events on retirement plans", Industrial and Labor Relations Review 39 (4):518-526.

Anderson, P. M., A. L. Gustman, and T. L. Steinmeier (1999), "Trends in male labor force participation and retirement: some evidence on the role of pensions and Social Security in the 1970s and 1980s", Journal of Labor Economics 17 (4 part 1):757-783.

Anderson, Patricia M. and Bruce D. Meyer (2001), "The distributional consequences of unemployment benefits and taxes", Working Paper, May 2001.

Anderson, Patricia M. and Bruce D. Meyer (1997), "Unemployment insurance takeup rates and the after-tax value of benefits", Quarterly Journal of Economics CXII:913-938.

Anderson, Patricia M. and Bruce D. Meyer (1997), "The effects of firm specific taxes and government mandates with an application to the U.S. Unemployment Insurance Program", Journal of Public Economics 65:119-144.

Anderson, Patricia M. and Bruce D. Meyer (1998), "Using a natural experiment to estimate the effects of the Unemployment Insurance Payroll Tax on wages, employment, claims and denials", National Bureau of Economic Research Working Paper 6808.

Anderson, Patricia M. and Bruce D. Meyer (1994), "The Effect of Unemployment Insurance Taxes and Benefits on Layoffs Using Firm and Individual Data", National Bureau of Economic Research Working Paper No. 4960. 
Anderson, Patricia M., and Meyer, Bruce D. (1993), "Unemployment insurance in the United States: layoff incentives and cross-subsidies", Journal of Labor Economics 11:S70-S95.

Atkinson, A. B. (1987), "Income Maintenance and Social Insurance", in Alan Auerbach and Martin Feldstein, eds., Handbook of Public Economics (North-Holland, Amsterdam)

Atkinson, Anthony B. (1993), "Have Social Security benefits seriously damaged work incentives in Britain?", in: A. B. Atkinson and G. V. Mogensen, eds., Welfare and work incentives: A North European perspective (Oxford University Press) 161-191.

Atkinson, Anthony B. and John Micklewright (1990), "Unemployment compensation and labor market transitions: a critical review", Journal of Economic Literature 29:1679-1727.

Autor, D. H. and M. G. Duggan (2001), "The rise in disability recipiency and the decline in unemployment", National Bureau of Economic Research Working Paper 8336.

Baily, Martin Neil (1977), "On the theory of layoffs and unemployment", Econometrica 45:1043-1064.

Baker, M. and D. Benjamin (1999), "Early retirement provisions and the labor force behavior of older men: evidence from Canada", Journal of Labor Economics 17 (4 Part 1):724-756.

Banks, James and Carl Emmerson (2000), "Public and private pension spending: principles, practice and the need for reform", Fiscal Studies 21:1-63.

Besley, Timothy and Anne Case (1994), "Unnatural experiments? Estimating the incidence of endogenous policies", National Bureau of Economic Research Working Paper W4956.

Black, D., K. Daniel, and S. Sanders (1998), The impact of economic conditions on participation in disability programs: evidence from the coal boom and bust (University of Kentucky, Lexington, KY; Monitor Company, New York, NY; Carnegie Mellon University, Pittsburgh, PA).

Blank, Rebecca M., and David E. Card (1990), "Recent trends in insured and uninsured unemployment: is there an explanation?", Quarterly Journal of Economics CVI:1157-1190.

Blau, D. M. (1997), "Social Security and the labor supply of older married couples", Labour Economics 4 (4):373-418.

Blinder, A. S., R. H. Gordon, and D. E. Wise (1980), "Reconsidering the work disincentive effects of Social Security", National Tax Journal 33 (4):431-442. 
Blinder, A. S., R. H. Gordon, and D. E. Wise (1990), "Social Security, bequests and the life cycle theory of saving: cross-sectional tests", in: Inventory theory and consumer behavior. (University of Michigan Press, Ann Arbor) 229-256.

Boskin, M.(1977), "Social Security and retirement decisions", Economic Inquiry 15 (1):1-25.

Boskin, M. J. (1986), Too many promises: the uncertain future of social security (Dow JonesIrwin, Homewood, IL).

Bound, J. (1989), “The health and earnings of rejected disability insurance applicants”, American Economic Review 79(3):482-503.

Bound, J. (1991), "The health and earnings of rejected disability insurance applicants: reply", American Economic Review 81(5):1427-1434.

Bound, J. and R. V. Burkhauser (1999), "Economic analysis of transfer programs targeted on people with disabilities", in: Orley Ashenfelter and David Card, eds., Handbook of Labor Economics 3C (Elsevier Science B.V., Amsterdam) 3417-3525.

Bound, J. and T. Waidmann (2000), "Accounting for recent declines in employment rates among the working-aged disabled", National Bureau of Economic Research Working Paper 7975.

Brechling, Frank (1977a), "Unemployment insurance taxes and labor turnover: summary of theoretical findings", Industrial and Labor Relations Review 30:483-494.

Brechling, Frank (1977b), "The incentive effects of the U.S. Unemployment Insurance Tax", in: Ronald Ehrenberg, ed., Research in Labor Economics 1 (JAI Press, Greenwich, CT) 41102.

Burdett, K. (1979), “Unemployment Insurance Payments as a Search Subsidy: A Theoretical Analysis”, Economic Inquiry 17:333-342.

Burtless, Gary S. (1990), "Unemployment insurance and labor supply: a survey", in: W. Lee Hansen and James F. Byers, eds., Unemployment Insurance (University of Wisconsin Press, Madison, WI).

Burtless, G. (1986), "Social Security, unanticipated benefit increases, and the timing of retirement", Review of Economic Studies 53(5):781-805.

Burtless, G. and A. H. Munnell (1991), "Does a trend toward early retirement create problems for the economy?", in: Alicia M. Munnell, ed., Retirement and public policy (National Academy of Social Insurance, Washington, DC). 
Butler, Richard (1983), “Wage and Injury Response to Shifting Levels of Workers' Compensation", in: J. Worrall, ed., Safety and the Workforce (Cornell University Press, Ithaca) 61-86.

Butler, Richard J., B. Delworth Gardner and Harold H. Gardner (1997), "Workers' Compensation Costs When Maximum Benefits Change", Journal of Risk and Uncertainty 15:259-269.

Butler, Richard J. and John D. Worrall (1991), "Claims Reporting and Risk Bearing Moral Hazard in Workers' Compensation”, Journal of Risk and Insurance 49:91-204.

Butler, Richard J., and John D. Worrall (1983), "Workers' compensation: benefit and injury claim rates in the seventies", Review of Economics and Statistics 50:580-589.

Butler, Richard J., and John D. Worrall (1985), "Work injury compensation and the duration of nonwork spells", Economic Journal 95:714-724.

Butler, R., D. Durbin, and N. Helvacian (1996), "Increasing claims for soft tissue in workers' compensation: cost shifting and moral hazard", Journal of Risk and Uncertainty 13:73-87.

Card, David and Phillip B. Levine (2000), "Extended benefits and the duration of UI spells: evidence from the New Jersey Extended Benefit Program”, Journal of Public Economics.

Card, David and Phillip B. Levine (1994): "Unemployment Insurance Taxes and the Cyclical and Seasonal Properties of Unemployment," Journal of Public Economics 53:1-29.

Card, David and Brian P. McCall (1996), "Is workers' compensation covering uninsured medical costs? Evidence from the 'Monday effect"', Industrial and Labor Relations Review 49:690-706.

Card, David and W. Craig Riddell (1993), "A comparative analysis of unemployment in Canada and the United States", in: David Card and Richard B. Freeman, eds., Small differences that matter (University of Chicago Press, Chicago, IL) 149-189.

Card, David and W. Craig Riddell (1997), "Unemployment in Canada and the United States: A Further Analysis," in B. Curtis Eaton and Richard G. Harris, eds., Trade, Technology and Economics: Essays in Honour of Richard Lipsey. (Edward Elgar, Cheltenham, UK).

Card, David and W. Craig Riddell (1993), "A Comparative Analysis of Unemployment in Canada and the United States", in: David Card and Richard B. Freeman, eds., Small Differences That Matter: Labor Markets and Income Maintenance in Canada and the United States. (University of Chicago Press and National Bureau of Economic Research, Chicago, IL). 
Carling, Kenneth, Per-Anders Edin, Anders Harkman, Bertil Holmlund. (1996), "Unemployment Duration, Unemployment Benefits, and Labor Market Programs in Sweden”, Journal of Public Economics 59:313-334.

Carling, Kenneth, Bertil Holmlund and Altin Vejsiu (2001), "Do Benefit Cuts Boost Job Finding? Swedish Evidence from the 1990s”, Economic Journal 111:766-790.

Chelius, James (1982), “The Influence of Workers' Compensation on Safety Incentives”, Industrial and Labor Relations Review 35:235-42.

Clark, Kim B., and Lawrence H. Summers (1982), "Unemployment insurance and labor market transitions", in: Martin Neil Baily, ed., Workers, Jobs, and Inflation (Brookings Institution, Washington, DC).

Classen, Kathleen P. (1979), "Unemployment insurance and job search", in: S. A. Lippman and J. J. McCall, eds., Studies in the economics of search (North-Holland, Amsterdam).

Corson, Walter and Walter Nicholson (1988), An Examination of Declining UI Claims During the 1980's, Unemployment Insurance Occasional Paper 88-3, Washington, DC: US Department of Labor - ETA.

Costa, D. (1998), The evolution of retirement: an American economic history, 1880-1990 (University of Chicago Press, Chicago, IL).

Crawford, V. and D. Lillien (1981), "Social Security and the retirement decision", Quarterly Journal of Economics 96(3):505-529.

Cullen, Julie and Jonathan Gruber. (2000), “Does Unemployment Insurance Crowd out Spousal Labor Supply?” Journal of Labor Economics 18(3):546-572.

Curington, William P. (1994), "Compensation for Permanent Impairment and the Duration of Work Absence: Evidence from Four Natural Experiments”, Journal of Human Resources 29(3):888-910.

Curington, William P., Amy Farmer, and W. David Allen (1997), "Retroactive Benefits in Income Replacement Programs: Results from a Modified Natural Experiment”,Southern Economic Journal 64(1):255-67.

Danziger, Sheldon, Robert Haveman, and Robert Plotnick (1981), "How income transfer programs affect work, savings, and the income distribution: a critical review", Journal of Economic Literature XIX:975-1028.

Deleire, T. (2000), "The wage and employment effects of the Americans with Disabilities Act", Journal of Human Resources 35(4):693-715. 
Devine, Theresa J. and Nicholas M. Kiefer (1991), Empirical labor economics: the search approach (Oxford University Press, New York, NY).

Diamond, P. A. and J. A. Hausman (1984), "The retirement and unemployment behavior of older men", in Henry Aaron and Gary Burtless, ed., Retirement and economic behavior: Studies in Social Economics series (Brookings Institution, Washington D.C.) 97-132.

Diamond, Peter and Eytan Sheshinski. (1995), "Economic aspects of optimal disability benefits", Journal of Public Economics 57:1-24.

Ehrenberg, Ronald G. (1988), "Workers' compensation, wages, and the risk of injury", in John F. Burton, Jr., ed., New perspectives in workers' compensation (ILR Press, Ithaca, NY) 7196.

Ehrenberg, Ronald G. and Ronald L. Oaxaca (1976), "Unemployment insurance, duration of unemployment, and subsequent wage gain", American Economic Review 66:754-766.

Emmerson, Carl and Andrew Leicester (2001), "A Survey of the UK Benefit System”, The Institute for Fiscal Studies, Briefing Note No. 13.

Engen, Eric M. and Jonathan Gruber (1995), "Unemployment insurance and precautionary saving”, National Bureau of Economic Research Working Paper W5252.

Feldstein, Martin S. (1974), "Unemployment compensation: adverse incentives and distributional anomalies", National Tax Journal 27:231-244.

Feldstein, Martin S. (1976), "Temporary layoffs in the theory of unemployment", Journal of Political Economy 84:837-57.

Feldstein, Martin S. (1978), "The effect of unemployment insurance on temporary layoff unemployment", American Economic Review 68:834-846.

Feldstein, M. and M. Liebman (2001), "Social Security", this volume.

Friedberg, L. (2000), "The labor supply effects of the Social Security Earnings Test", Review of Economics and Statistics 82(1):48-63.

Fuchs, V. R., A. B. Krueger, and J. M. Poterba (1998), "Economists' views about parameters, values, and policies: survey results in labor and public economics", Journal of Economic Literature 36(3):1387-1425.

Gardner, John A. (1991), "Benefit increases and system utilization: the Connecticut experience", Workers Compensation Research Institute. 
Gordon, R. H. and A. S. Blinder (1980), "Market wages, reservation wages, and retirement decisions", Journal of Public Economics 14(2):277-308.

Gritz, R. Mark, and Thomas MaCurdy (1990), "The influence of unemployment insurance on the unemployment experiences of young workers", Working Paper, Hoover Institution.

Gruber, J. (1997), "The consumption smoothing benefits of unemployment insurance", American Economic Review 87(1):192-205.

Gruber, J. and B. C. Madrian (1995), "Health-insurance availability and the retirement decision", American Economic Review 85(4):938-948.

Gruber, J. and P. Orszag (2000), "Does the Social Security Earnings Test affect labor supply and benefits receipt?", National Bureau of Economic Research Working Paper 7923.

Gruber, J. and D. A. Wise. (1999), "Social Security and retirement around the world: introduction and summary", National Bureau of Economic Research Conference Report.

Gruber, Jonathan, and Alan Krueger (1991), "The incidence of mandate employer-provided insurance: lessons from Workers' Compensation Insurance", in: David Bradford, ed., Tax Policy and the Economy 5 (National Bureau of Economic Research, Cambridge, MA) 111-143.

Gustman, Alan L. (1982), "Analyzing the relation of unemployment insurance to unemployment", in: Ronald Ehrenberg, ed., Research in Labor Economics 5 (JAI Press, Greenwich, CT).

Ham, John C. and Samuel A. Rea, Jr. (1987), "Unemployment Insurance and Male Unemployment Duration in Canada”, Journal of Labor Economics 5(3):325-353.

Hamermesh, Daniel S. (1977), Jobless Pay and the Economy. (Johns Hopkins University Press, Baltimore, MD).

Holmlund, Bertil (1983), "Payroll Taxes and Wage Inflation: The Swedish Experience", Scandinavian Journal of Economics 85(1):1-15.

Holmlund, Bertil (1998), "Unemployment Insurance in Theory and Practice”, Scandinavian Journal of Economics 100:113-141.

Hunt, Jennifer. (1995), “The Effect of Unemployment Compensation on Unemployment Duration in Germany", Journal of Labor Economics. 13(1):88-120.

Hurd, M. D. and M. J. Boskin (1984), "The effect of Social Security on retirement in the early 1970s", Quarterly Journal of Economics 99(4):767-790. 
International Labour Organization (2001), "Cost of Social Security", (Geneva, Switzerland). Available from www.ilo.org/public/english/protection/socsec/publ/css/cssindex.htm.

Ippolito, R. A. (1998), "Disparate savings propensities and national retirement policy", in: O. S. Mitchell and S. J. Schieber, eds., Living with defined contribution pensions: Remaking responsibility for retired men (University of Pennsylvania Press, Philadelphia, PA) 247272.

Johnson, William, and Jan Ondrich, (1989), "The duration of post-injury absences from work", mimeo., Syracuse University.

Kahn, J. A. (1988), "Social Security, liquidity, and early retirement", Journal of Public Economics 35(1):97-117.

Katz, Lawrence F., and Bruce D. Meyer (1990), "Unemployment insurance, recall expectations and unemployment outcomes", Quarterly Journal of Economics CV:973-1002.

Katz, Lawrence F., and Bruce D. Meyer (1990), "The impact of the potential duration of unemployment benefits on the duration of unemployment", Journal of Public Economics 41:45-72.

Killingsworth, Mark R. (1983), Labor supply (Cambridge University Press, New York).

Kniesner, Thomas J., and John D. Leeth (1995), Simulating workplace safety policy (Kluwer Academic Publishers, Boston, MA).

Krueger, Alan B. (1990a), "Incentive effects of Workers' Compensation Insurance", Journal of Public Economics 41:73-99.

Krueger, Alan B. (1990b), "Workers' Compensation Insurance and the duration of workplace injuries", National Bureau of Economic Research Working Paper 3253.

Krueger, Alan B. and John F. Burton, Jr. (1990), “The Employers' Cost of Workers' Compensation Insurance: magnitudes, Determinants, and Public Policy”, Review of Economics and Statistics 72:228-240.

Krugman, Paul. (2001), “Outside the box”, The New York Times, July 11, p. A17.

Lee, C. (1998), "The rise of the welfare state and labor-force participation of older males: evidence from the pre-Social Security era", American Economic Review 88(2):222-226.

Leonard, J. S. (1979), "The Social Security Disability Insurance program and labor force participation", National Bureau of Economic Research Working Paper 392. 
Levine, Phillip B. (1993), "Spillover effects between the insured and uninsured unemployed", Industrial and Labor Relations Review 47:73-86.

Margo, R. A. (1993), "The labor force participation of older Americans in 1900: further results", Exploration in Economic History 30(4):409-423.

McCall, Brian (1996), "Unemployment Insurance Rules, Joblessness, and Part-Time Work", Econometrica 64(3):647-82.

Meyer, Bruce D. (1990), "Unemployment insurance and unemployment spells", Econometrica 58:757-782.

Meyer, Bruce D. (1992a), "Using natural experiments to measure the effects of unemployment insurance", working paper, Northwestern University.

Meyer, Bruce D. (1992b), "Quasi-experimental evidence on the effects of unemployment insurance from New York State”, working paper.

Meyer, Bruce D. (1995a), "Natural and Quasi- Experiments in Economics", Journal of Business \& Economic Statistics 13:151-162.

Meyer, Bruce D. (1995b), "Lessons from the U.S. unemployment insurance experiments", Journal of Economic Literature 33:91-131.

Meyer, Bruce D. and Dan T. Rosenbaum (1996), "Repeat use of unemployment insurance", National Bureau of Economic Research Working Paper 5423.

Meyer, Bruce D., W. Kip Viscusi and David Durbin (1995), "Workers' compensation and injury duration: evidence from a natural experiment", American Economic Review 85:322-340.

Moen, J. (1987), "The labor of older men: a comment", Journal of Economic History 47(3):761767.

Moffitt, R. A. (1987), "Life-cycle labor supply and Social Security: a time-series analysis", in: Gary Burtless, ed., Work, health, and income among the elderly (The Brookings Institution, Washington D.C.).

Moffitt, Robert (1985), "Unemployment Insurance and the Distribution of Unemployment Spells," Journal of Econometrics 28:85-101.

Moffitt, R., and W. Nicholson (1982), "The effect of unemployment insurance on unemployment: the case of federal supplemental benefits", The Review of Economics and Statistics 64:1-11. 
Mont, D, J.F. Burton Jr. and V. Reno (2000), Workers' Compensation: benefits, coverage, and costs, 1997-1998, new estimates ( National Academy of Social Insurance, Washington, DC).

Moore, Michael J., and W. Kip Viscusi (1989), "Promoting safety through Workers' Compensation: the efficacy and net wage costs of injury insurance", Rand Journal of Economics 20:499-515.

Moore, Michael J., and W. Kip Viscusi (1990), Compensation mechanisms for job risks: wages, Workers' Compensation, and product liability (Princeton University Press, Princeton, NJ).

Mortensen, Dale T. (1977), "Unemployment insurance and job search decisions", Industrial and Labor Relations Review 30:505-517.

Mortensen, Dale T. (1986), "Job search and labor market analysis", in: Orley C. Ashenfelter and Richard Layard, eds., Handbook of labor economics (North Holland, Amsterdam) 849919.

Mortensen, Dale T. (1990), "A structural model of UI benefit effects on the incidence and duration of unemployment," in: Yoram Weiss and Gideon Fishelson, eds., Advances in the theory and measurement of unemployment. (St. Martin's Press, New York).

National Academy of Social Insurance (2000), “Workers' compensation: benefits, coverage, and costs, 1997-1998, new estimates”, (Washington, DC).

National Foundation for Unemployment Compensation \& Workers' Compensation (1998), Highlights of state unemployment compensation laws (NFUCWC, Washington, DC).

Nelson, W.J. Jr. (1988a), “Workers' compensation: coverage, benefits and costs, 1985”, Social Security Bulletin 51(1):4-9.

Nelson, W.J. Jr. (1988b), “Workers’ compensation: 1980-84 benchmark revisions”, Social Security Bulletin 51(7):4-21.

Nelson, W.J. Jr. (1991), “Workers' compensation: coverage, benefits and costs, 1988”, Social Security Bulletin 54(3):12-20.

Neuhauser, Frank and Steven Raphael (2001), “The Effect of an Increase in Worker's Compensation Benefits on the Duration and Frequency of Benefit Receipt", working paper, University of California, Berkeley.

Nickell, Stephen (1998), “Unemployment: Questions and Some Answers”, Economic Journal 108:802-816. 
Parnes, H. S. (1988), "The retirement decision", in: M. Borus, H. Parnes, S. Santell, and B. Seidman, eds., The older worker (Industrial Relations Research Association, Wisconsin).

Parsons, D. O. (1980), "The decline in male labor force participation", Journal of Political Economy 88(1):117-134.

Parsons, D. O. (1991), "The health and earnings of rejected disability insurance applicants: comment", American Economic Review 81(5):1419-1426.

Pellechio, A. J. (1979), "Social Security financing and retirement behavior", The American Economic Review 69(2):284-287, Papers and Proceedings of the Ninety-First Annual Meeting of the American Economic Association.

Pellechio, A. J. (1981), "Social Security and the decision to retire", National Bureau of Economic Research Working Paper W0734.

Pencavel, J. H. (1986), "Labor supply of men: a survey", in: Orley Ashenfelter and Richard Layard, eds., Handbook of labor economics, vol. 1, 3-102.

Peracchi, Franco and Finis Welch (1994), Journal of Labor Economics 12(2):210-42.

Quinn, J. F. (1987), "Life-cycle labor supply and Social Security: a time-series analysis: comment", in: Gary Burtless, ed., Work, health, and income among the elderly. Studies in Social Economics series (Brookings Institution, Washington, D.C.) 220-228.

Quinn, J. F. (1999), Has the early retirement trend reversed? (Boston College, Chestnut Hill, MA).

Quinn, J. F., R. V. Burkhauser, and D. A. Myers (1990), Passing the torch. The influence of economic incentives on work and retirement (W.E. Upjohn Institute for Employment Research, Kalamazoo, MI).

Ransom, R. L. and R. Sutch (1986), "The labor of older Americans: retirement of men on and off the job 1870-1937", Journal of Economic History 46(1):1-30.

Rejda, G. E. (1999), Social insurance and economic security (Prentice Hall: Upper Saddle River, $\mathrm{NJ})$.

Riddell, W. Craig (1999), “Canadian Labour Market Performance in International Perspective”, Canadian Journal of Economics 32:1097-1134.

Riddell, W. Craig and Andrew Sharpe (1998), "The Canada-US Unemployment Rate Gap: An Introduction and Overview", Canadian Public Policy 24:1-37. 
Roed, Knut and Tao Zhang (2000), "Does Unemployment Compensation Affect Unemployment Duration", working paper, Frisch Centre for Economic Research, Oslo.

Ruser, John W. (1985), "Workers' Compensation Insurance, experience-rating, and occupational injuries", Rand Journal of Economics 16:487-503.

Ruser, John W. (1991), "Workers' compensation and occupational injuries and illnesses", Journal of Labor Economics 9:325-350.

Ruser, John W. (1998), "Does workers' compensation encourage hard to diagnose injuries?", Journal of Risk and Insurance 65:101-124.

Rust, J. and C. Phelan (1997), "How Social Security and Medicare affect retirement behavior in a world of incomplete markets", Econometrica 65(4):781-831.

Smith, Robert S. (1990), "Mostly on Monday: is workers' compensation covering off-the-job injuries?" in: Philip S. Borba and David Appel, eds., Benefits, costs, and cycles in workers' compensation (Kluwer, Boston, MA).

Social Security Administration, Office of Research, Evaluation and Statistics (2000), "Fast facts and figures about Social Security", (Washington, D.C.) Available from www.ssa.gov/statistics/fast_facts/index.html.

Social Security Administration (2001), "Social Security Disability planner", (Washington, D.C.) Available from www.ssa.gov/dibplan/dqualify6.htm.

Solon, Gary (1985), "Work incentive effects of taxing unemployment benefits", Econometrica 53:295-306.

Summers, Lawrence H. (1989), "Some simple economics of mandate benefits", American Economic Review, Papers and Proceedings 79:177-183.

Topel, Robert H. (1983), "On Layoffs and Unemployment Insurance," American Economic Review 73:541-559.

U.S. Chamber of Commerce (2000), Analysis of workers' compensation laws, 2000. (U.S. Chamber of Commerce, Washington, DC).

U.S. House of Representatives, Committee on Ways and Means (various years), Green Book, Background material and data on programs within the jurisdiction of the Committee on Ways and Means. (U.S. Government Printing Office, Washington, DC). 
Viscusi, W. Kip and Michael J. Moore (1987), "Workers' compensation: wage effects, benefit inadequacies, and the value of health losses", Review of Economics and Statistics 66:249-261.

Welch, Finis (1977), "What have we learned from empirical studies of unemployment insurance?", Industrial and Labor Relations Review 30:451-461.

Worrall, John D., Richard J. Butler, Phillip Borba, and David Durbin (1988), "Estimating the exit rate from workers' compensation: new hazard rate estimates", working paper. 


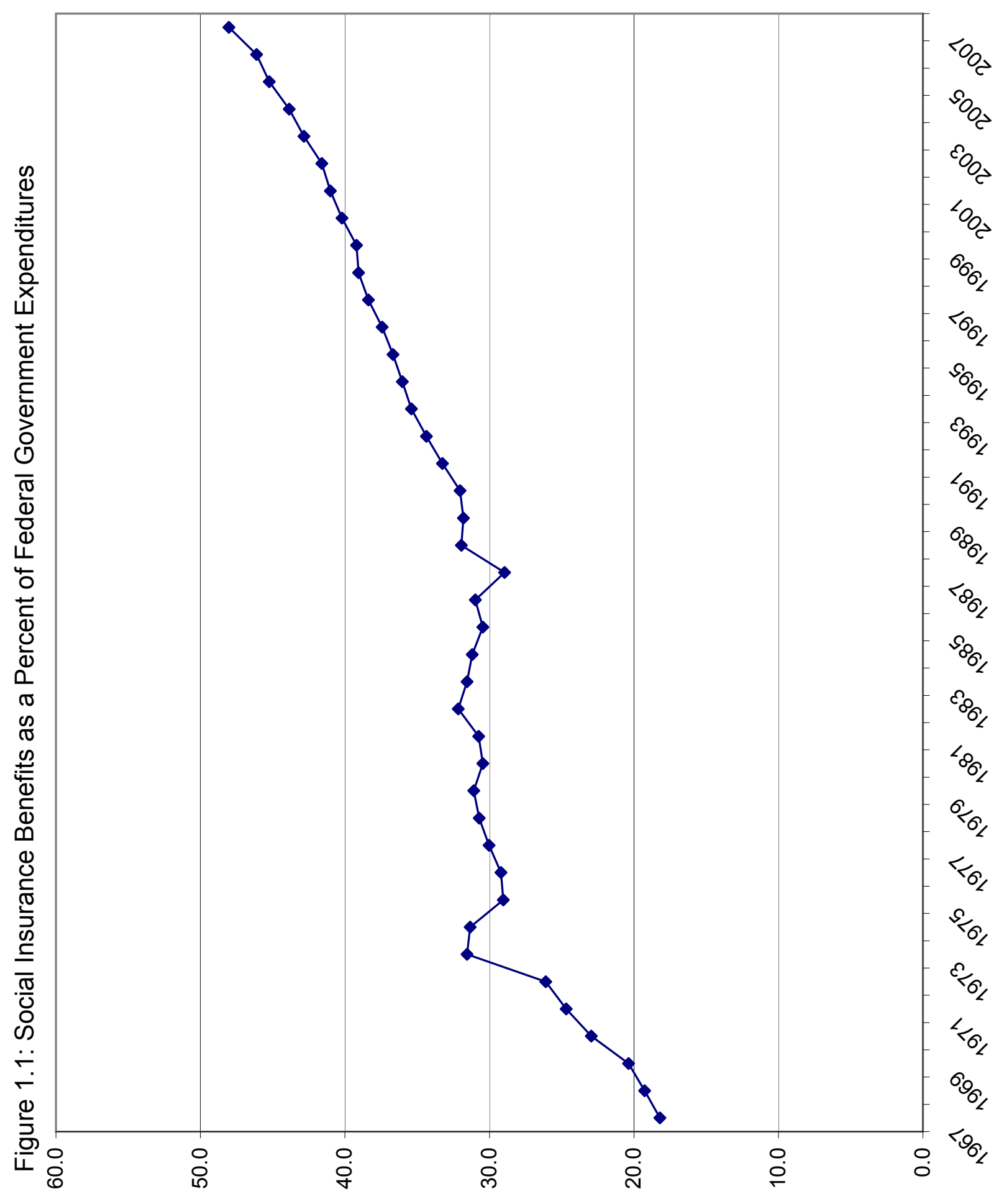




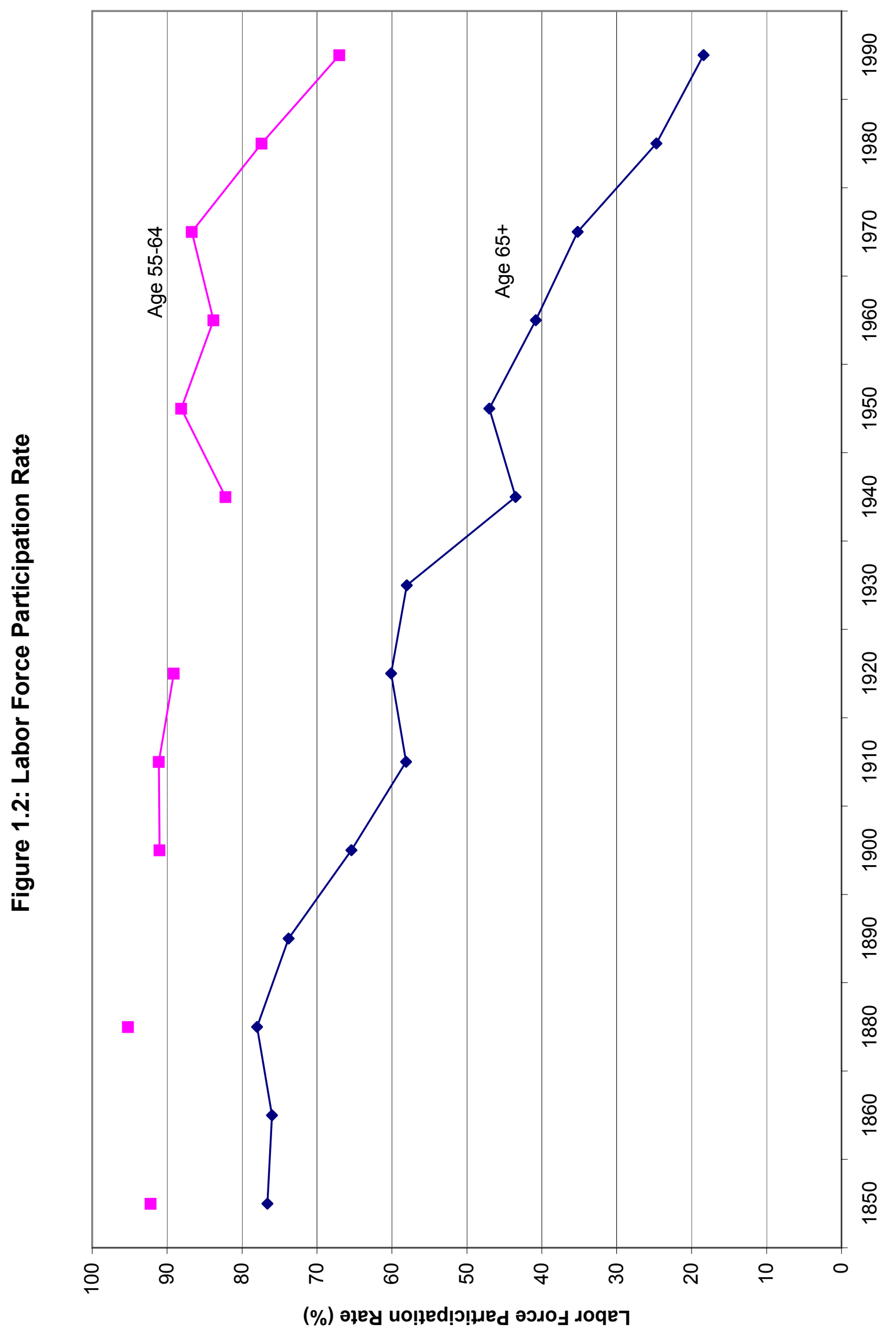



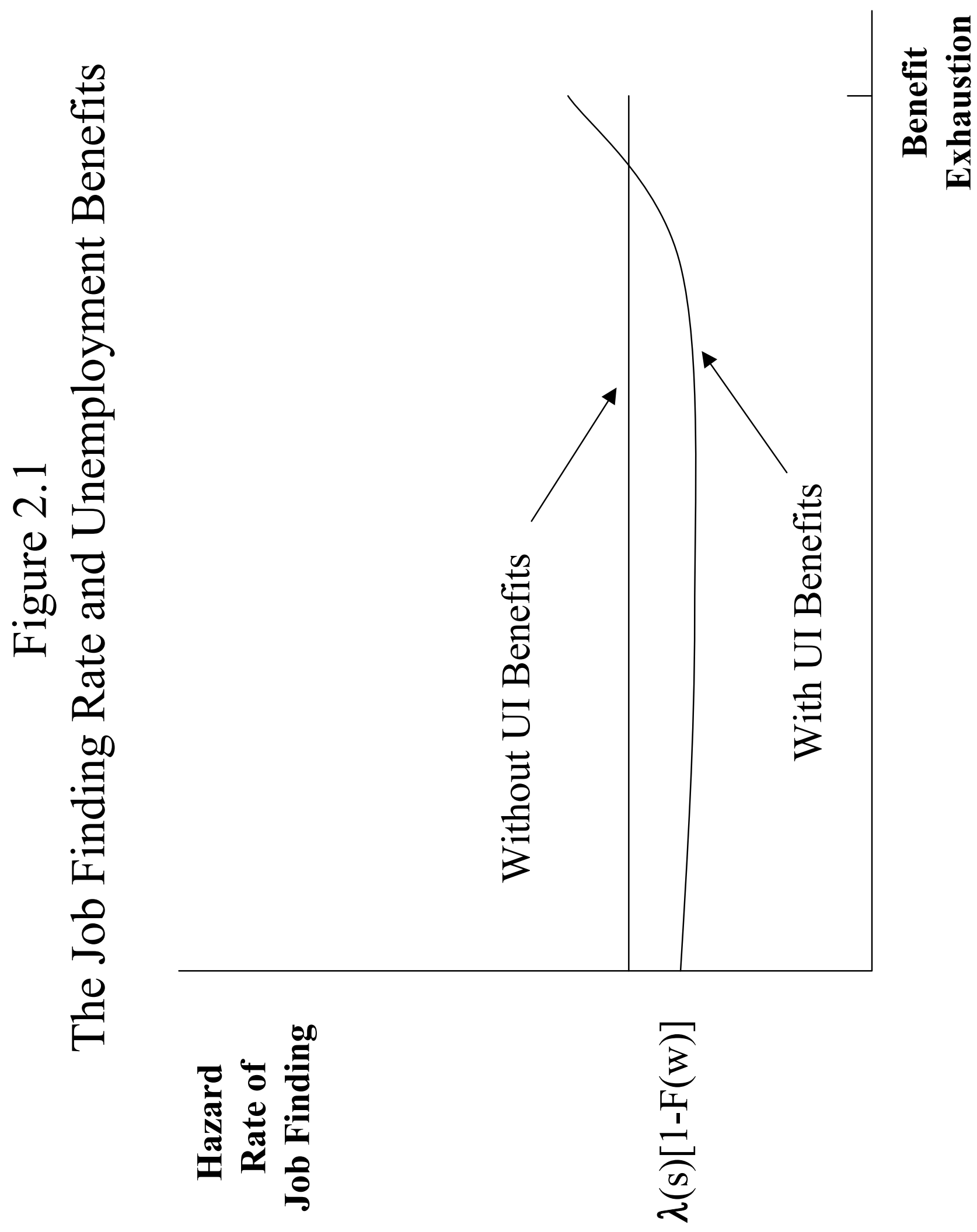


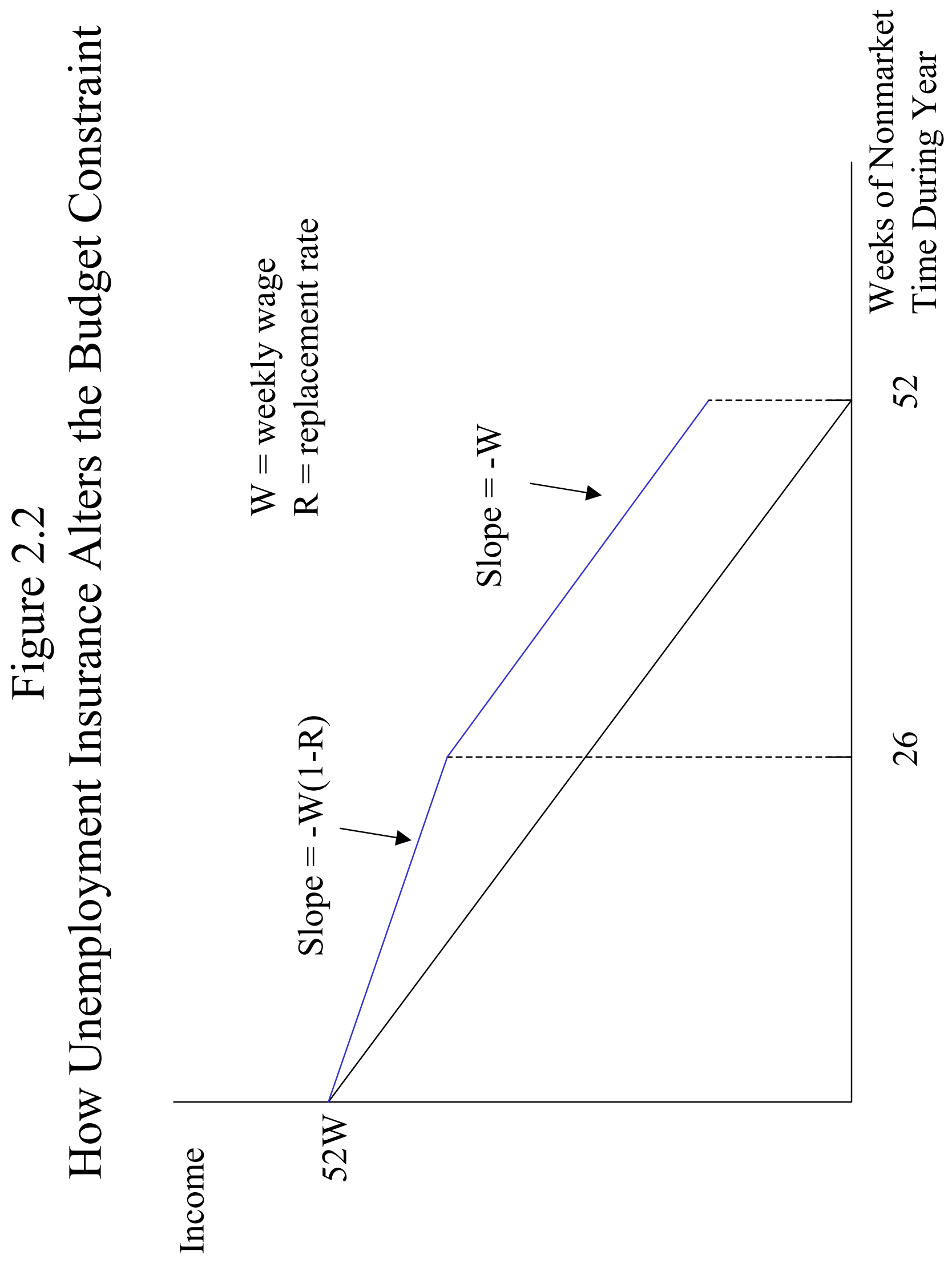




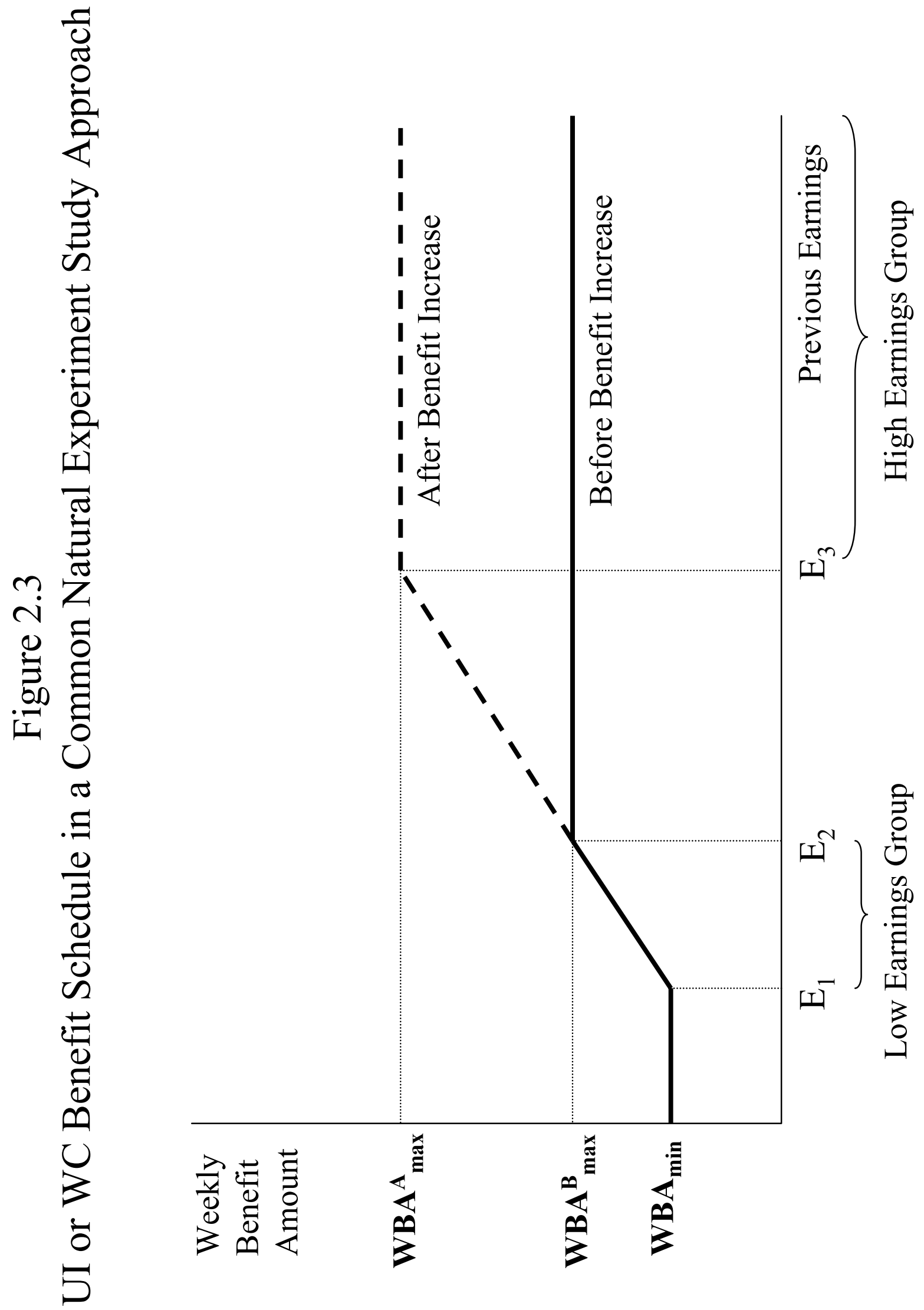


Labor Force Participation Rate and Soc. Sec. Wealth

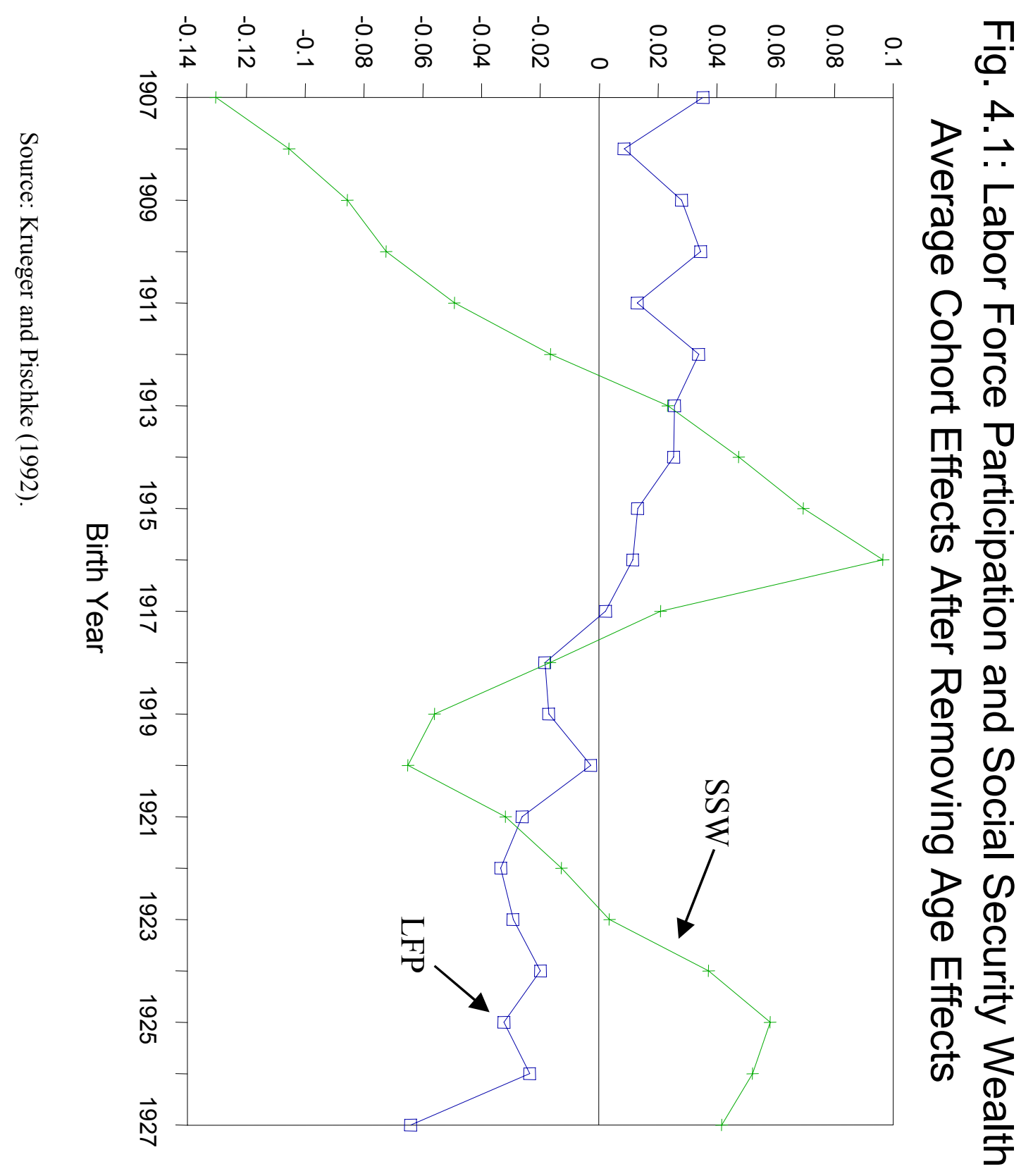




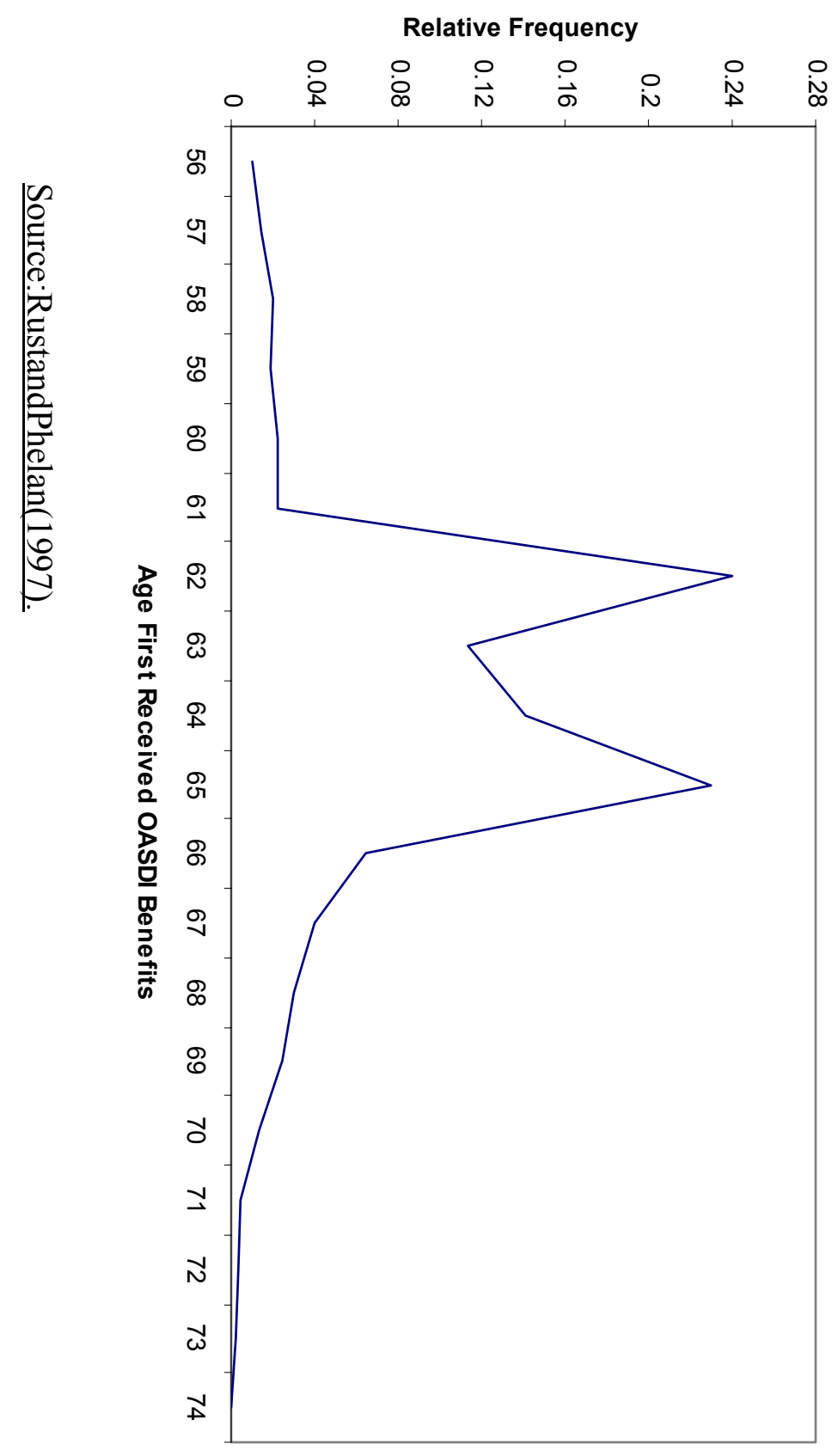



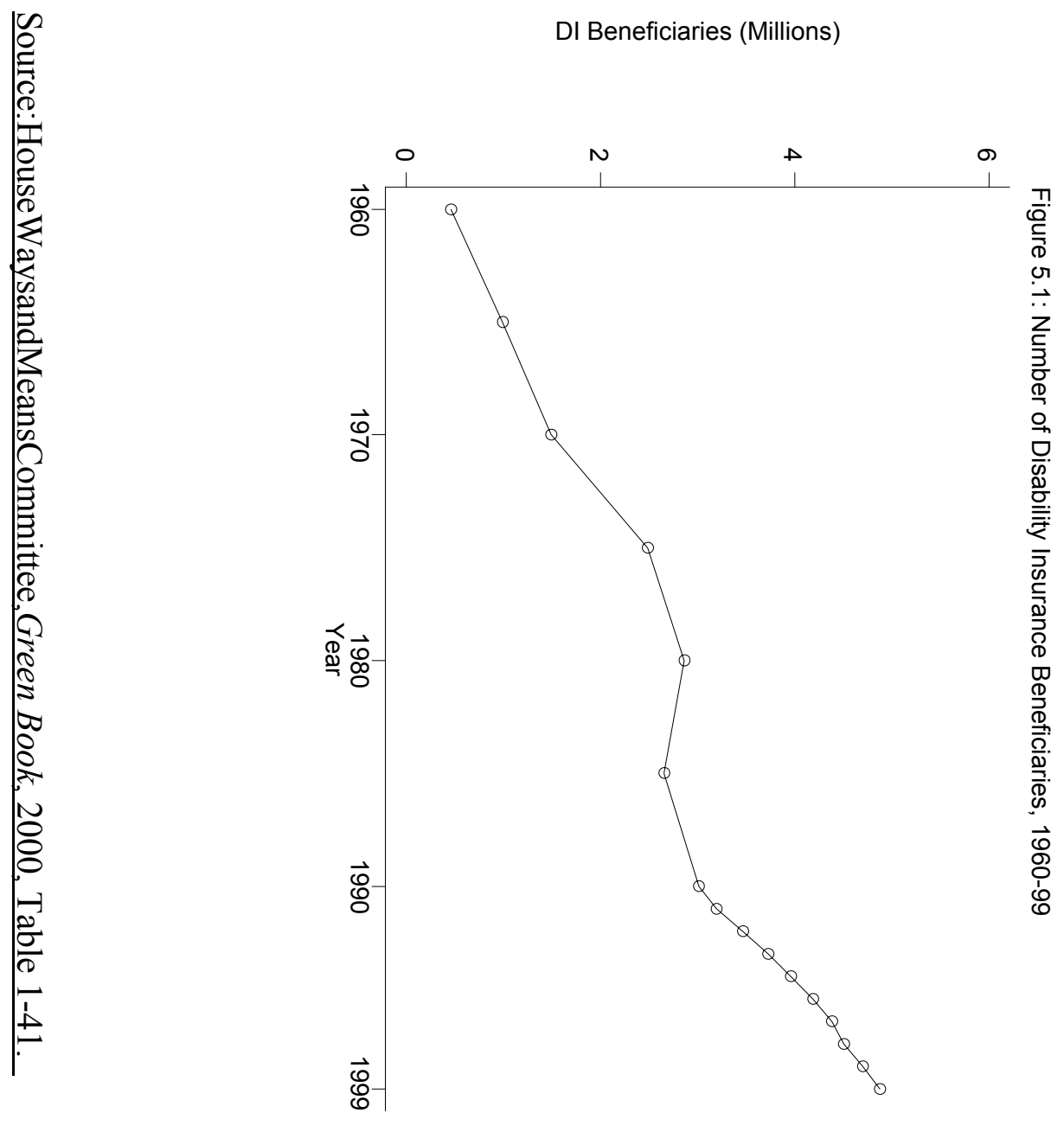


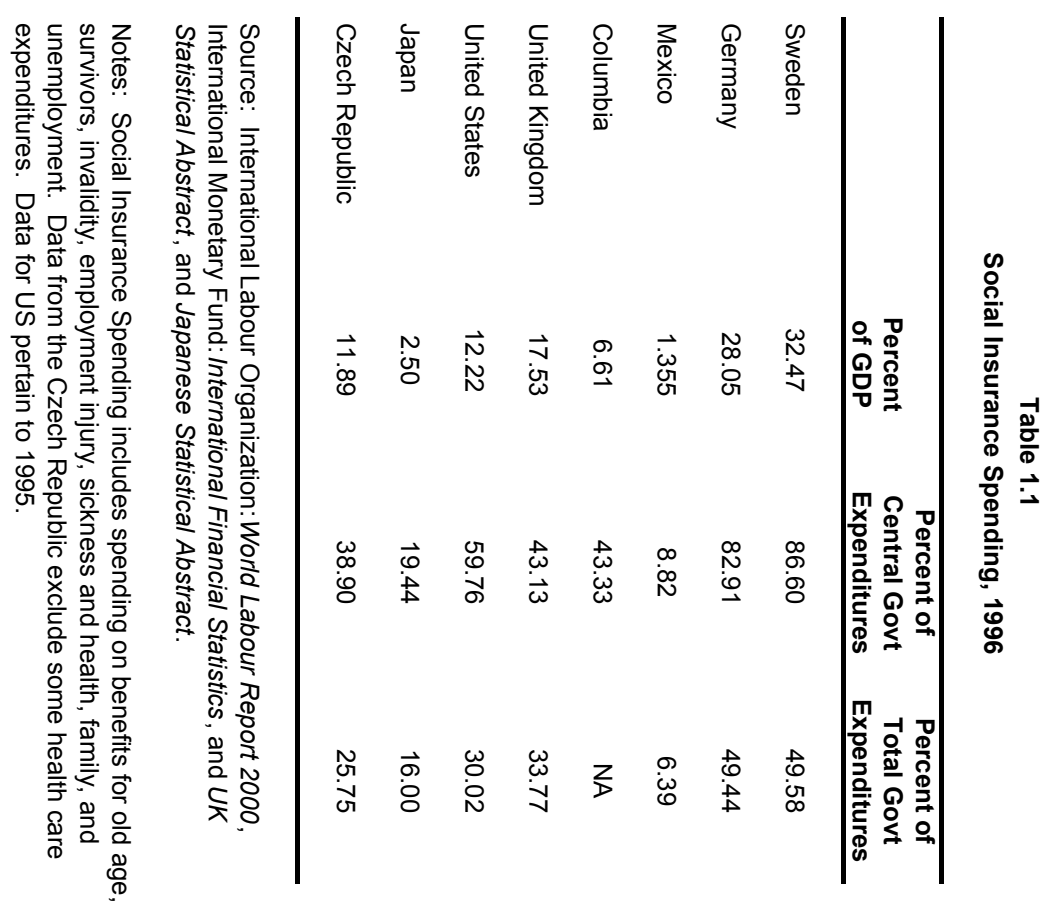




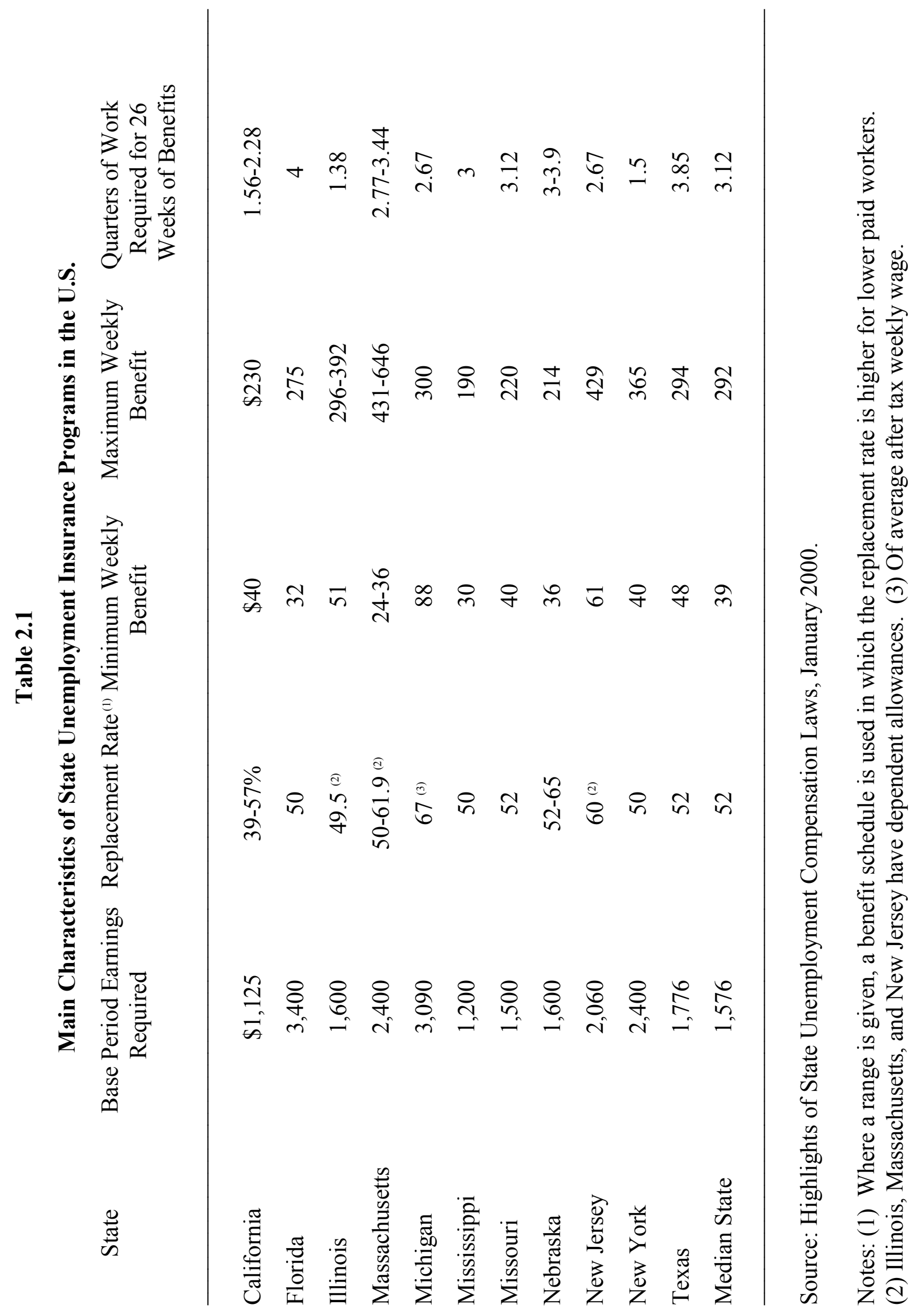


Table 2.2

International Comparisons of Expenditures on Unemployment Insurance and Workers Compensation
Country
Unemployment Insurance
Employment Injuries (Workers’ Compensation)

\begin{tabular}{ccccc} 
& \% of GDP & \$US millions & \% of GDP & \$US millions \\
\hline Canada & 2.52 & 13,776 & 0.85 & 4,624 \\
Denmark & 4.54 & 6,113 & 0.24 & 325 \\
Germany & 3.40 & 65,049 & 0.60 & 11,427 \\
Japan & 0.46 & 19,788 & 0.25 & 10,744 \\
Sweden & 2.95 & 5,460 & 0.81 & -- \\
United Kingdom & 0.25 & 2,445 & 0.74 & 41,654 \\
United States & 0.50 & 28,334 & & - \\
& & & & 402 \\
\end{tabular}

Sources: International Labour Organization, Cost of Social Security 1990-96.

Note: Expenditures include cash and in-kind benefits, and administrative and other expenditures. All figures are in nominal dollars and pertain to 1993 (1991 for the United States). 
Table 2.3

\section{Studies of Unemployment Insurance and the Incidence of Layoffs}

\author{
Empirical Specification
}

Feldstein (1978). Linear regression of temporary layoff probability on the after-tax UI replacement rate, controlling for age, union status, race, marital status, gender, a linear effect of the wage, and industry and occupation (in some specifications).

Topel (1983). Estimation of time constant layoff and reemployment hazard rate using cross-section data on labor force status and unemployment. Key UI variable is subsidy rate $b((1 / 1-t))-e$, where $b$ is the benefit, $t$ is the income tax rate and $e$ is fraction of the cost of a marginal layoff that the firm pays through experience rating.

Card and Levine (1994). Estimation of annual and seasonal temporary layoff, permanent layoff and other unemployment rates. Linear models for the probability of unemployment with e (see above for definition) as the main regressor are used, with state, state*year and industry*year controls in some specifications.

Anderson and Meyer (1994). Linear probability models of temporary job separations and all job separations with firm specific measure of e (see above for definition) and controls for past firm layoffs. Some specifications difference the data to remove firm and individual fixed effects.

Data and Identification

Findings

U.S. March 1971 Current Population Survey (CPS) data for experienced labor force members who were not labor for re-entrants and not selfemployed. Identified by differences in benefits across states and individuals within state.

U.S. March 1975 CPS data on full-time, full-year labor force participants. Identified by differences in benefit and experience rating schedules across states interacted with industry unemployment rates.

U.S. CPS outgoing-rotation-group data for 5 industries in 36 states from 1978-1985. Identified by differences in experience rating schedules across states interacted with industry unemployment rates.

U.S. Continuous Wage and Benefit History (CWBH) administrative data on both workers and firms from 6 states during 1978-1984. Identified by the differential effects of changes in state tax schedules on different firms.
Elasticity of temporary layoff unemployment rate with respect to the replacement rate ranging from .74 to .91 . "The average UI benefit replacement rate implied by the current law can account for about half of temporary layoff unemployment."

“...the layoff unemployment rate would have been about 30 percent lower if the subsidy to unemployment caused by the current UI system had been eliminated." Argues that most of the effect is through incomplete experience increasing layoffs.

"We estimate that a move to complete experiencerating would reduce the temporary layoff unemployment rate by about 1.0 percentage point ( or roughly 50 percent) in the trough of a recession, and by about the same amount in the lowest demand months of the year."

"Our preferred estimates imply that incomplete experience rating is responsible for over twenty percent of temporary layoffs." 
Table 2.4

Studies of Unemployment Insurance and Benefit Takeup

Empirical Specification

Corson and Nicholson (1988). Aggregate claims ratio regressed on replacement rate $=$ average weekly benefit of recipients divided by average weekly wage of employed.

Micro claims data regressed on variable for income taxation of UI, but replacement rate not used.

Blank and Card (1991). Aggregate claims ratio adjusted for estimated eligibility regressed on replacement rate $=$ average weekly benefit of recipients divided by average weekly wage of employed.

Micro claims data regressed on state average replacement rate. No variable for income taxation of UI included.

Meyer (1992). Difference in difference analysis of claim incidence by earnings group, industry and region.

Anderson and Meyer (1997). Linear and logit models of UI receipt conditional on separation. Explanatory variables include logarithms of: weekly benefit, 1-tax on benefits, 1-tax on earnings, and potential duration of benefits. Some specifications with flexible controls for past earnings, state, and state*time.
Data and Identification

Findings

U.S. state by year aggregate data on the fraction of Elasticity over 0.5 . unemployed that receive UI.

Panel Study of Income Dynamics (PSID)

Large effect of benefit taxation variable. individual data on UI claims.

U.S. state by year aggregate data on the fraction of

Replacement rate elasticities of 0.32 to 0.58 . unemployed that receive UI.

Panel Study of Income Dynamics (PSID) individual data on UI claims.

New York administrative data on UI claims from 1988 and 1989. Identification comes from a 36 percent increase in the maximum benefit.

U.S. CWBH data on both workers and firms from 6 states during 1978-1984. Identified by differences in benefit schedules across states, changes in these schedules, changes in income taxation of benefits.
Insignificant effect of replacement rate. Coefficient usually of "wrong" sign.

"The numbers are consistent with large effects of the higher benefits on the relative incidence of claims."

Elasticity of benefit takeup with respect to benefits of 0.33 to 0.60 . Slightly smaller elasticities with respect to (1-tax on benefits). Elasticities of takeup with respect to potential duration about half as large as those with respect to the benefit level. 
Table 2.5

\section{Studies of Unemployment Insurance and the Duration of Unemployment in the U.S.}

Empirical Specification

Classen (1979). Linear and log-linear regression of unemployment duration on benefits using deviations of relationship from linearity at benefit maximum as an estimate of benefit effects. Tobit models were also estimated.

Solon (1985). Hazard model for exit from

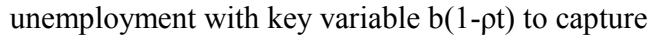
taxation of benefits.

Moffitt (1985). Flexible discrete hazard model of exit from unemployment with explanatory variables for benefit level, potential duration at start of spell, past wages, and state unemployment rate

Meyer (1990) and Katz and Meyer (1990b). Hazard model for exit from unemployment with nonparametric baseline hazard and variables for benefit level, and measures of time until benefits run out. Includes controls for state unemployment and past wages, and state indicator variables.

Meyer (1992a). Comparisons of durations of those filing 3 months before and after 17 benefit increases. Most of increases due to automatic cost-of-living adjustments. Estimates with and without controls for demographics.

Meyer (1992b). Difference in difference analysis of claim duration with extensive controls.

Card and Levine (2000). Hazard models of exit from unemployment receipt.
Data and Identification

U.S. Continuous Wage and Benefit History (CWBH) adiministrative data from Arizona from the year before and year after a 1968 benefit increase.

U.S. CWBH data for Georgia before and after the introduction of income taxation of UI benefits for high income families.

U.S. CWBH data for 13 states 1978-1983. Identification from differences in benefit schedules across states and changes in benefits and potential duration over time.

Subset of Moffit (1985) data with some recoding. Same as Moffitt, but the inclusion of state indicators weights identification toward changes in schedules and differential treatment across states of those with different levels of earnings.

U.S. CWBH data for six states. Identification of benefit effects comes from changes in benefits due to cost-of-living adjustments in period of high inflation.

See Table 2.4

U.S. administrative data for New Jersey. Examines program that offered 13 weeks of 'extended benefits' for 6 months in 1996. The program was part of a political compromise over funding care for indigent hospital patients.
Findings

Benefit elasticity of 0.6 in levels and 1.0 in logarithms.

After-tax benefit elasticity of duration equal to 1.0.

"The results indicate that a 10-percent increase in the UI benefit increases spells by about half a week and that a 1 -week increase in potential duration increases spells by about 0.15 weeks."

These numbers suggest a benefit elasticity of about 4 and a potential duration elasticity of 0.34 .

Elasticity of duration with respect to the benefit of 0.8 , and with respect to potential duration of 0.5 .

A range of estimates, but central tendency of elasticity of duration with respect to the benefit amount of 0.6.

Duration elasticities of .24 to .42 , though several estimates are smaller.

Elasticity of duration with respect to potential duration of 0.1 . 
Table 2.6

Studies of Unemployment Insurance and the Duration of Unemployment Outside of the U.S.

\section{Empirical Specification}

Ham and Rea (1987). Models the hazard from unemployment as a function of a polynomial of the duration of unemployment, initial entitlement and its square, weekly benefits and wages, and the provincial and industrial unemployment rates. Estimation is by maximum likelihood.

Hunt (1995). Models exit from unemployment in a competing risks hazard framework, combined with a difference in differences approach. Control variables are an individual's age group, the time period, the interaction of time and age (treatment groups), and various demographic variables. Identification comes from the differential effect of the policy changes on the treatment and control groups.

Carling, Edin, Harkman, and Holmlund (1996). The hazard of leaving unemployment (to any alternative) is modeled using an unrestricted baseline hazard, and is estimated semiparametrically. Explanatory variables include indicators for receiving UI benefits, or KAS (cash assistance, which gives smaller benefits for a shorter period of time) age, education, training, gender, citizenship, and the regional unemployment rate.

Roed and Zhang (2000). Flexible hazard rate model.

Carling, Holmlund and Vejsiu (2001), Flexible hazard rate model of exits to employment and competing risks model of exits to employment, labour market programmes, and non-participation.
Data and Identification

Findings
Canadian Employment and Immigration Longitudinal Labour Force Files with weekly data on men aged 18-64, for 1975-80. Identification comes from legislative changes in the benefit rate, individuals with weekly wages above the maximum earnings, and changes in weeks of entitlement.

German Socioeconomic Panel public use file, for the years 1983-88. 2,236 individuals under age 57. One policy change reduced benefits to the childless unemployed, and three policy changes extended the duration of benefits to unemployed individuals that were of a certain age (aged $49+$ for the first, aged $44+$ for the second, and aged $42+$ for the third). The control group consisted of unemployed individuals that were 41 years old or less.

Sweden. Non-disabled unemployed workers under 55 registered at public employment agencies in 3 months of 1991. Identification from variation in claimant status across individuals. UI recipients were members of a UI fund for at least 12 months, and had worked for a certain number of days in the past 12 months. KAS provided compensation for those not covered by UI, and who met work or school requirements and included labor force entrants.

Norway. Register data on all unemployment spells between August 1990 and December 1999. Benefit variation due to changes in indexation over the year is used for identification.

Sweden. Register-based longitudinal data from 19941996. Data from before and after cut in replacement rate from $80 \%$ to $75 \%$.
Benefit effect of wrong sign or insignificant. The potential duration coefficients were both significant in all specifications. An increase in the initial potential duration of one week was estimated to increase expected duration by .26 to .33 weeks (an elasticity of $1.02-1.33$ )

The extension of benefits lowered by $46 \%$ the hazard from unemployment for those aged 44-48, but the other benefit extensions had insignificant effects. For those 44-48 the implied elasticity of mean duration with respect to the maximum duration of UI was 2.27. In several cases, the extensions cut escapes to employment and out of the labor force. The cut in benefits for the childless significantly increased employment. The author notes that many of the effects are implausibly large.

Elasticity of exit to employment with respect to the benefit level is estimated at -.06 .

Elasticity of hazard with respect to benefit of 0.35 for men and -0.15 for women.

"Our implied elasticity of the hazard rate with respect to benefits is about $1.6 \ldots .$. 
Table 2.7

Studies of Other Unemployment Insurance Effects on Labor Supply

\section{Empirical Specification}

McCall (1996). The exit from unemployment to full-time or part-time work is modeled using a competing risks hazard model with explanatory variables including an indicator for UI receipt, the replacement rate, the disregard (amount that can be earned without reducing benefits) and interactions of these variables.

Cullen and Gruber (2000). The labor supply of wives modeled as a linear function of potential UI benefits, demographic variables, the unemployment rate, the average wage of women similar to the wife, and lagged husband's job characteristics. Dependent variables are the share of months employed and average hours worked per month. OLS, Tobit and 2SLS estimates with benefits received instrumented for using potential benefits.

\section{Data and Identification}

U.S. CPS Displaced Worker Supplements from 1986, 1988, 1990, and 1992. Cross-state differences in disregard and changes in disregards (state fixed effects specifications).

U.S. SIPP data from the 1984-88 and 1990-92 waves. Married couples where both husband and wife are between 25 and 54. 2560 spells of unemployment.
Findings

Significant effect of disregard on probability of part-time employment during the first three months of joblessness.

Estimates of the implied income elasticity of labor supply for wives ranges from -0.49 using OLS to -1.07 using 2 SLS. In a specification check, potential UI benefits also had a significant negative effect on the labor supply of women with employed husbands, suggesting that these estimates may overstate the true effect of UI benefits. 
Table 3.1

Main Characteristics of State Workers' Compensation Programs in the U.S.

State Minimum Weekly Maximum Weekly Replacement Rate Waiting Period Retroactive Period Benefit Benefit

\begin{tabular}{|c|c|c|c|c|c|}
\hline California & $\$ 126.00^{(1)}$ & $\$ 490.00$ & $662 / 3 \%$ & 3 days & 2 weeks \\
\hline Florida & 20.00 & 541.00 & $662 / 3$ & 7 days & 2 weeks \\
\hline Illinois & $100.90-124.30^{(2)}$ & 899.81 & $662 / 3$ & 3 days & 2 weeks \\
\hline Massachusetts & 149.93 & 749.69 & 60 & 5 days & 3 weeks \\
\hline Michigan & 170.00 & 611.00 & $80^{(4)}$ & 7 days & 2 weeks \\
\hline Mississippi & $25.00^{(3)}$ & 303.35 & $662 / 3$ & 5 days & 2 weeks \\
\hline Missouri & 40.00 & 578.48 & $662 / 3$ & 3 days & 2 weeks \\
\hline Nebraska & $49.00^{(1)}$ & 487.00 & $662 / 3$ & 7 days & 6 weeks \\
\hline New Jersey & 151.00 & 568.00 & 70 & 7 days & 8 days \\
\hline New York & $40.00^{(1)}$ & 400.00 & $662 / 3$ & 7 days & 2 weeks \\
\hline Texas & 80.00 & 531.00 & $70^{(5)}$ & 7 days & 4 weeks \\
\hline Median State & 100.00 & 529.00 & $662 / 3$ & 3 days & 2 weeks \\
\hline
\end{tabular}

Source: 2000 Analysis of Workers' Compensation Laws: U.S. Chamber of Commerce.

Notes: (1) In California the minimum is actual earnings if less than the amount listed. (2) Illinois' minimum benefit increases if additional dependents are present. (3) In Mississippi the minimum does not apply in cases of partial disability. (4) In Michigan the replacement rate is a percent of after-tax earnings. (5) In Texas the replacement rate is $75 \%$ if earnings are less than $\$ 8.50$ per hour. 
Table 3.2

Financial Characteristics of Workers Compensation and Unemployment Insurance Programs

Workers Compensation
Unemployment Insurance

\begin{tabular}{|c|c|c|c|c|}
\hline Year & $\begin{array}{c}\text { Benefit Payments } \\
(\$ \text { millions })\end{array}$ & $\begin{array}{c}\text { Costs } \\
\text { (\$ millions) }\end{array}$ & $\begin{array}{c}\text { Benefit Payments } \\
(\$ \text { millions })\end{array}$ & $\begin{array}{c}\text { Tax Collections } \\
(\$ \text { millions })\end{array}$ \\
\hline 1980 & 13,618 & 22,256 & 14,070 & 15,010 \\
\hline 1981 & 15,054 & 23,014 & 15,580 & 15,630 \\
\hline 1982 & 16,407 & 22,764 & 21,240 & 15,950 \\
\hline 1983 & 17,575 & 23,048 & 28,850 & 18,010 \\
\hline 1984 & 19,685 & 25,122 & 16,340 & 24,060 \\
\hline 1985 & 22,470 & 29,320 & 14,360 & 24,450 \\
\hline 1986 & 24,647 & 33,964 & 15,700 & 22,880 \\
\hline 1987 & 27,317 & 38,095 & 15,080 & 24,180 \\
\hline 1988 & 30,703 & 43,284 & 13,280 & 23,820 \\
\hline 1989 & 34,316 & 47,955 & 13,500 & 21,750 \\
\hline 1990 & 38,237 & 53,123 & 16,860 & 21,360 \\
\hline 1991 & 42,170 & 55,216 & 24,420 & 20,630 \\
\hline 1992 & 45,668 & 57,394 & 36,770 & 23,010 \\
\hline 1993 & 45,330 & 60,820 & 35,070 & 25,230 \\
\hline 1994 & 44,586 & 60,475 & 26,220 & 27,960 \\
\hline 1995 & 43,373 & 57,054 & 20,990 & 28,900 \\
\hline 1996 & 42,065 & 55,057 & 22,000 & 28,550 \\
\hline 1997 & 40,586 & 52,040 & 20,300 & 28,200 \\
\hline 1998 & 41,693 & 52,108 & 19,410 & 27,370 \\
\hline 1999 & -- & -- & 20,720 & 26,480 \\
\hline
\end{tabular}

Sources: Workers' Compensation: Benefits, Coverage, and Costs (1980-84 Benchmark Revisions, 1985, 1988, and 1997-1998 New Estimates). Committee on Ways and Means Green Book, (1990, 1998, 2000)

Note: All amounts are in nominal dollars. 
Table 3.3

Studies of Workers' Compensation and the Incidence of Injuries or Claims

$\begin{array}{lll}\text { Unit of Observation } & \text { Dependent } & \text { Benefit Elasticity } \\ \text { and Sample } & \text { Variable } & \end{array}$

\begin{tabular}{|c|c|c|c|}
\hline Chelius (1982) & $\begin{array}{l}\text { U.S. State by two-digit SIC } \\
\text { manufacturing industry; } 36 \text { states } \\
\text { from } 1972 \text { to } 1975 .\end{array}$ & Injuries per 100 full-time workers. & 0.14 \\
\hline \multirow[t]{2}{*}{ Ruser (1985) } & $\begin{array}{l}\text { U.S. State by three-digit SIC } \\
\text { manufacturing industry; }\end{array}$ & $\begin{array}{l}\text { Injuries per } 100 \text { full-time workers. } \\
\text { Injuries with lost workdays per } 100\end{array}$ & 0.062 \\
\hline & $\begin{array}{l}\text { unbalanced panel of } 41 \text { states } \\
\text { from } 1972 \text { to } 1979 .\end{array}$ & full-time workers. & 0.116 \\
\hline Butler (1983) & $\begin{array}{l}\text { U.S. Manufacturing industries by } \\
\text { year; } 15 \text { industries over } 32 \text { years } \\
\text { in South Carolina. }\end{array}$ & $\begin{array}{l}\text { Closed workers' compensation cases } \\
\text { reported in the fiscal year per } \\
\text { worker. }\end{array}$ & 0.290 \\
\hline Butler and Worrall (1983) & $\begin{array}{l}\text { U.S. State by year: } 35 \text { states from } \\
1972 \text { to } 1978 \text {. }\end{array}$ & $\begin{array}{l}\text { Temporary total claims of non self- } \\
\text { insured firms per worker. }\end{array}$ & 0.344 \\
\hline Krueger (1990a) & $\begin{array}{l}\text { U.S. Individuals in } 47 \text { states in } \\
1984 \text { and } 1985 .\end{array}$ & Workers' compensation claims. & 0.45 \\
\hline Krueger and Burton (1990) & $\begin{array}{l}\text { U.S. state level data for } 29 \text { states } \\
\text { in } 1972,1975,1978 \text {, and } 1983 .\end{array}$ & $\begin{array}{l}\text { Premiums per employee or manual } \\
\text { rate. }\end{array}$ & $\begin{array}{l}\text { Not significantly different } \\
\text { from zero. }\end{array}$ \\
\hline Butler and Worrall (1991) & $\begin{array}{l}\text { U.S. state level data for } 1954- \\
1981 \text {. }\end{array}$ & Workers' compensation claim costs. & 0.68 \\
\hline \multirow[t]{2}{*}{$\begin{array}{l}\text { Butler, Gardner and Gardner } \\
\text { (1997) }\end{array}$} & $\begin{array}{l}\text { U.S. Individuals at a large } \\
\text { nationwide firm during 1990- } \\
1993 \text {. }\end{array}$ & Frequency of disability claims. & $\begin{array}{l}-0.45 \text { to } 1.24 \\
\text { (with median of } 0.78 \text { ) }\end{array}$ \\
\hline & & Indemnity cost per worker. & $\begin{array}{l}0.06 \text { to } 2.90 \\
\text { (with median of } 1.27 \text { ) }\end{array}$ \\
\hline
\end{tabular}


Table 3.4

Study

Studies of Workers' Compensation and the Duration of Claims

Unit of Observation Dependent

Variable

Benefit Elasticity and Sample

Low-back injuries in Illinois.

Low-back injuries in 13 states.

Worrall, Butler, Borba and Durbin (1988)

Meyer, Viscusi and Durbin (1995)

Krueger (1990b)

Gardner (1991)

Curington (1994)

Aiuppa and Trieschmann (1998)

Neuhauser and Raphael (2001)
All injuries in Kentucky (19791981) and Michigan (1981-1982).

All injuries in Minnesota in 1986.

All injuries in Connecticut in19851990.

All injuries in New York 1964-1983

France. Administrative region level data from Caisse Nationale for years 1973-91.

California Workers' Compensation Institute Administrative Data from 2 years before and after 1994 and 1995 benefit increases.
Length of claim using hazard models.

$0.2-0.4$

Length of claim using hazard models.

Length of claims; comparisons of $\quad 0.3-0.4$

means and $\log$ (duration).

Length of claims; comparisons of $>1.5$ means and $\log$ (duration).

Mean length of claims.

Severe impairment durations.

$0.7-1.3$

Minor impairment durations

$0.1-0.2$

Indemnity costs per injured

0.78

employee.

Duration of temporary disability claims.

$0.25-0.35$, but much larger with selection correction 
Table 4.1: Summary of Selected Studies of Social Security and Labor Supply

\section{Study}

Hurd and Boskin (1984)

Krueger and Pischke (1992)

Burtless (1986)

Rust and Phelan (1997)

Blau (1997)

Moffitt (1987)

\section{Description}

Examine the effect of Social Security benefits in 1969 on retirement rates of older men. The cohorts under study experienced a largely unanticipated $52 \%$ increase in Social Security Wealth between 1968 and 1972

Examine effect of Social Security benefit generosity and the growth in benefits from delaying retirement one year on labor force participation, weeks worked and retirement.
Proposes a model of retirement behavior for anticipated and unanticipated changes in real social security benefits and how the retirement decision is affected by unanticipated changes.

\section{Analysis and Identification}

Examine conditional retirement rates for birth cohorts over time, and estimate logit models of whether men retire in a particular year as a function of Social Security wealth, wages, and wealth, and interactions of these variables. Sample consists of white married men age 58-67 with non-working spouses. Identification from cross-sectional nonlinear differences in the Social Security benefit.

Identification is based on the Social Security benefit notch, which lowered benefits for the 1917-21 cohort. Use cohort level data on men from Current Population Survey, 1976-88.
Use Retirement History Survey to analyze unanticipated SS benefits from '69-'72 on male workers who still have to make a retirement decision. Unlike previous work, the econometric model accounts for non-linear relationship between goods consumption and retirement age.

Estimate a dynamic programming model of the labor supply and participation in Social Security decisions, with incomplete loan, annuity and health insurance markets. Use data on a panel of individuals initially aged 58-63 from 1969 to 1979 from the Retirement History Survey.

\section{Findings}

Based on cross-sectional estimates, the increase in Social Security benefits can account for the entire 8.2 percentage point fall in labor force participation of older men from 1968 to 1973 . Evidence also suggests that liquidity constraints cause a substantial number of men to retire upon reaching age 62 , when they initially qualify for benefits.

A decline in Social Security wealth for the notch cohort did not significantly affect labor supply, although the increase in benefits from delaying retirement is significantly related to labor force participation. Social Security wealth effect is less than onesixth as large as Hurd and Boskin find.

Finds that the long-run effect of the unanticipated increases in benefits decreased the average retirement age by .17 years and increased the probability of retiring between age 62 and 65 by 2 percent. Also, found that the effect would have been greater had the benefit increase come sooner.

For a sample of men whose only retirement income is Social Security, they find that liquidity constraints can account for the spike in retirement rates at age 62 and 65 . They also find that the fact that individuals do not qualify for Medicare until age 65 induces some individuals to work longer than otherwise to be covered employer-sponsored health insurance.

The model accounts for the features of the differing labor force decisions of the joint labor force behavior of older married couples. The analysis looks at the transitions of these joint labor force decisions.

Uses time-series data to estimate the wealth elasticity of labor supply from variations in unexpected changes in net social security wealth over the life cycle. Aggregate data are constructed from the March Current Population Survey, 19551981.
Finds that although there is a negative relationship between social security wealth and labor supply, the timing of the labor supply response does not correspond well to changes in social security wealth. 
Diamond and

Hausman (1984)

Studies the effect of bad health, unemployment and permanent income on retirement behavior. Focuses on the impact of uncertainty.

Examine the determinants of the

Gordon and Blinder (1980) retirement decisions of white men age 5867.

Baker and Benjamin (1999)

Gruber and Orszag (2000)

Examine the effect of the introduction of early retirement provisions in Canada's public pension plans on pension receipt and labor market behavior of men age 6064.

Examine the impact of the social security earnings test on the labor supply behavior of older men and women. The earnings test reduces immediate payments to beneficiaries of certain ages who are still working and whose current labor income exceeds a given threshold, although benefits are subsequently increased to compensate for any reduction.
Estimate hazard models of the retirement decision, probit models of whether involuntarily unemployed workers become retired, and competing risk hazard models of retirement or reemployment using data from the National Longitudinal Survey of Older men.

Estimate a structural model of the retirement decision using data from the 1969,1971 , and 1973 waves of the Longitudinal Retirement History Survey. Jointly estimate via maximum likelihood structural models of the reservation wage and the market wage. Use these estimates to predict an individual's retirement decision, under the assumption that men retire when their reservation wage exceeds their market wage.

Emphasize that cross-sectional studies of the effect of retirement income on retirement status overstate the substitution effect of retirement income because people may have retired prior to being eligible for benefits. Both social security and private pensions have a positive effect on the probability of retirement.

Find that the Social Security system has little or no effect on retirement decisions. Instead, retirement is driven primarily by the effects of aging on market and reservation wages and by the incentives set up by private pension plans.

Exploit the fact that early retirement provisions were introduced sequentiallyin 1984 in Quebec and in 1987 in the rest of Canada--to estimate a differencein-difference model of the effect of the policy change. Data are from the individual files of the 1982-83 and 198590 Survey of Consumer Finance.

Identification based on changes in the parameters of the earnings test between 1973 and 1998. Data on earnings, hours worked, and social security receipt of men and women ages 59-75 are from the March Current Population Survey, 1974-99
Find that the introduction of early retirement provisions led to significant increases in benefit take-up among men age $60-64$ but did not increase incidence of early retirement.

Find that the earnings test exerts no robust influence on the labor supply decisions of men. Find some evidence of an effect on women's labor supply decisions. 